\title{
Experimental Determination of Desorption Rates and of Heats of Desorption
}

\author{
J. W. Porter* and S. S. Penner $†$ \\ Jet Propulsion Center, California Institute of Technology, Pasadena, California
}

(Received 13 May 1963)

\begin{abstract}
Gas discharge rates through a de Laval nozzle from a closed chamber have been measured for $\mathrm{Ar}, \mathrm{He}$, and $\mathrm{CO}_{2}$. The effective desorption rates from vessels containing sand and silica gel have also been determined at various temperatures by measuring the time rate of pressure decay in the chamber. The experimental data have been used, in conjunction with a theoretical expression for diffusioncontrolled desorption rates, to estimate heats of desorption from silica gel. Results have been obtained that are in approximate agreement with estimates made by other investigators using more conventional procedures.
\end{abstract}

\section{INTRODUCTION}

$\mathrm{S}^{\mathrm{c}}$ UCCESSFUL measurements of chemical reaction rates during nozzle flow have been performed ${ }^{1}$ for the mixture $2 \mathrm{NO}_{2} \rightleftharpoons \mathrm{N}_{2} \mathrm{O}_{4}$ by using a largescale apparatus. Cruder data have been obtained, by a number of investigators, on rocket engines of various sizes. In order to utilize the full potential of this technique for studying the interplay between chemical reaction rates and subsonic or supersonic flow, it is clearly desirable to develop a small-scale laboratory apparatus which can be constructed at low cost. Unfortunately, the use of a small, closed vessel as gas source reduces the (pseudo) steady flow conditions to very short periods of time, thereby leading to the requirement that kinetic studies be performed with very high time resolution. As a first step for increasing the testing time, we have studied experimentally the discharge rates of $\mathrm{He}$, Ar, and $\mathrm{CO}_{2}$ through a de Laval nozzle from a small, closed reaction vessel containing sand or silica gel beads. The results and an approximate interpretation for the measurements are described in the following sections.

The experimental technique developed by us appears to be useful for the empirical determination of desorption rates from porous solid particles under isothermal conditions (see Appendix A for justification of the assumed isothermal conditions) during the initial stages of desorption. The dependence on temperature of the rates of desorption of $\mathrm{Ar}, \mathrm{He}$, and $\mathrm{CO}_{2}$ from silica gel has been investigated. A theoretical expression has been developed for the rate of desorption of gas from a porous solid under our experimental conditions (see Appendix B). Study of the data derived from the decay of chamber

\footnotetext{
* Present address: University of West Virginia, Morgantown, West Virginia.

+ Present address: School of Science and Engineering, University of California at San Diego, La Jolla, California. ${ }^{1}$ P. P. Wegener, Phys. Fluids 2, 264 (1959).
}

pressure with time indicates that the assumed model for desorption from porous spheres yields reasonable results for the heats of desorption of $\mathrm{He}, \mathrm{Ar}$, and $\mathrm{CO}_{2}$ from silica gel.

\section{OUTLINE OF THEORETICAL CONSIDERATIONS}

\section{A. Derivation of Equations for the Chamber Pres- sure as a Function Time for Systems Without Mass Addition}

Consider adiabatic expansion of a perfect gas, characterized by a constant value of $\gamma$, from a closed container through a de Laval nozzle. The continuity equation is

$$
-d(\rho V) / d t=\rho_{\mathrm{t}} v_{\mathrm{t}} A_{\mathrm{t}},
$$

where $V$ denotes the constant chamber volume, $\rho_{\mathrm{t}}=p_{\mathrm{t}} / R_{\mathrm{g}} T_{\mathrm{t}}$ is the gas density at the nozzle throat if $R_{\mathrm{g}}$ denotes the gas constant per unit mass, $T_{\mathrm{t}}=$ $[2 /(\gamma+1)] T$ represents the temperature at the nozzle throat when the chamber temperature is $T$, $p_{\mathrm{t}}=[2 /(\gamma+1)]^{\gamma /(\gamma-1)} p$ represents the nozzle throat pressure when the chamber pressure is $p$, and the flow velocity at the nozzle throat is $v_{\mathrm{t}}=$ $\left(\gamma R_{\mathrm{g}} T_{t}\right)^{\frac{1}{2}}$. Hence Eq. (1) may be written in the form

$$
\begin{aligned}
& -\frac{d}{d t}\left[\left(\frac{p}{p_{0}}\right)\left(\frac{T_{0}}{T}\right)\right] \\
& \quad=\frac{p}{p_{0}}\left(\frac{T_{0}}{T}\right)^{\frac{1}{2}} \frac{A_{\mathrm{t}}\left(\gamma R_{\mathrm{g}} T_{0}\right)^{\frac{1}{2}}}{V}\left(\frac{2}{\gamma+1}\right)^{(\gamma+1) / 2(\gamma-1)},
\end{aligned}
$$

where the subscript 0 identifies initial conditions in the chamber.

\section{Isothermal Expansion in Chamber}

For isothermal gases in a closed chamber, the integral of Eq. (2) becomes

$$
p / p_{0}=\exp \left(-t / t^{*}\right) \text { for } T=T_{0},
$$

where

$$
t^{*}=\left[V / A_{\mathrm{t}}\left(\gamma R_{\mathrm{g}} T_{0}\right)^{\frac{1}{2}}\right](1 / \Gamma)=m_{0} / \dot{m}_{0}
$$


and

$$
\Gamma=[2 /(\gamma+1)]^{(\gamma+1) / 2(\gamma-1)} \simeq 0.1047 / \gamma+0.5048
$$

Here $t^{*}$ represents a characteristic time involving chamber and nozzle parameters, $m_{0}=\rho_{0} V$ is the initial mass of gas in the chamber, and $\dot{m}_{0}=$ $\rho_{0} A_{\mathrm{t}}\left(\gamma R_{\mathrm{g}} T_{0}\right)^{\frac{2}{2}} \Gamma$ represents the initial mass flow rate of gas through the nozzle.

\section{Adiabatic Equations with Modified Values of $\gamma$}

For adiabatic expansion in the chamber

$$
T / T_{0}=\left(p / p_{0}\right)^{\left(\gamma_{0}-1\right) / \gamma_{0}},
$$

where we use the symbol $\gamma_{\mathbf{c}}$ to denote an effective constant value of the specific heat ratio in the chamber. After integration between the limits $p / p_{0}=1$ at $t=0$ and $p / p_{0}$ at $t$, Eq. (2) now leads to the result

$$
\left(p / p_{0}\right)^{\left(1-\gamma_{0}\right) / 2 \gamma_{\mathrm{o}}}=1+\frac{1}{2}\left(\gamma_{\mathrm{c}}-1\right) t / t^{*} .
$$

In the limit, as the gas-bead system in the chamber assumes an infinite specific heat, $\gamma_{\mathrm{c}}$ approaches unity and Eq. (6) reduces to the isothermal case described by Eq. (3).

In comparing the theoretical formulas with experimental data, it is reasonable to treat $\gamma_{\mathrm{c}}$ as a variable parameter that is adjusted in order to fit the experimental data. In this manner, we may use the proximity of $\gamma_{\mathrm{c}}$ to unity as an indication of the efficiency with which heat is transferred from the beads to the gases.

It should be noted that the statements $T=T_{0}$ and $\left(p / p_{0}\right)=\left(T / T_{0}\right)^{\gamma_{\mathrm{c}} /\left(\gamma_{\mathrm{c}}-1\right)}$ constitute effectively two different energy conservation assumptions, both of which correspond to unobservable limiting cases. The isothermal limit $\left(T=T_{0}\right)$ will constitute a fair approximation if the heat transfer rates from the solids to the gases are very high. The adiabatic limit for unmodified $\gamma$, on the other hand, represents a reasonable approximation if the discharge rates are fast compared with the heat transfer rates.

\section{B. Derivation of Expressions for the Chamber Pres- sure as a Function of Time for Limiting Cases Involving Heat and Mass Transfer From the Beads to the Gas}

For strongly adsorbed gases, mass addition by desorption (rather than heat transfer) will dominate the observed pressure-time behavior. This limiting condition should obtain when the rate of decay of chamber pressure with time for chambers filled with beads is appreciably slower than the rate of decay for the case of discharge of gases from an isothermal chamber.

\section{Mass Addition Under Isothermal Conditions in the Chamber}

As a first step in interpreting the experimental results, we assume that the desorption rates are constant and independent of the instantaneous value of the chamber pressure. We may obtain some insight into the physical conditions under which this assumed desorption model applies by noting that desorption rates from highly porous materials (e.g., silica gel beads) should be controlled by diffusion processes. $^{2,3}$

If the average pore radius is small compared to the mean free path of the gas molecules but large compared to the dimensions of a molecule, the flow of gas in the pores will occur by Knudsen diffusion. The average pore radius for silica gel satisfies this condition (see Appendix B for details). A concentration gradient in the gas phase within the pores produces a concentration gradient in the adsorbed phase on the pore walls, i.e., the flow of gas in a porous solid such as silica gel occurs by diffusion in the gas phase and by surface diffusion in the adsorbed phase. Of course, only molecules possessing sufficient energy to separate from local adsorption sites will be able to migrate over the surface. The activation energy required for surface diffusion on a surface is equal to, or smaller than, the heat of adsorption (for details see, for example, Fig. 12, reference 4 .)

The solution of the diffusion problem involves the external density, $\rho(t)$, as a boundary condition. We have used for this density the expression for an isothermal system with a constant rate of mass addition. The density boundary condition has then been justified by showing that results derived from it are, approximately, consistent with the assumption of a constant rate of mass addition under isothermal conditions.

For a constant rate of mass addition, $\dot{m}_{\mathrm{d}}$, Eq. (1) becomes

$$
-\frac{d}{d t}\left[\left(\frac{p}{p_{0}}\right)\left(\frac{T_{0}}{T}\right)\right]=\frac{p}{p_{0}}\left(\frac{T_{0}}{T}\right)^{\frac{1}{2}} \frac{1}{t^{*}}-\nu_{0},
$$

where $\nu_{0}=\dot{m}_{\mathrm{d}} / m_{0}$ is a characteristic desorption frequency and the definition of $t^{*}$ involves $V$, the

2 S. Brunauer, The Adsorption of Gases and Vapors, Vol 1: Physical Adsorption (Princeton University Press, Princeton, New Jersey, 1945), pp. 454-471.

${ }^{3}$ G. Damköhler, Z. Phys. Chem. A174, 222 (1935).

${ }^{4}$ P. C. Carman and F. A. Raal, Proc. Roy. Soc. (London) A209, 38 (1951). 


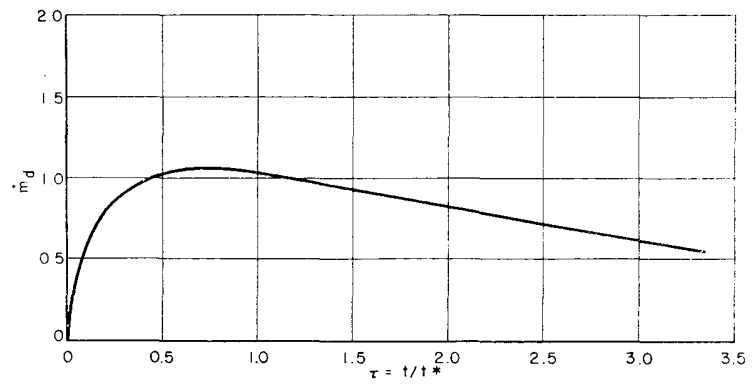

FIg. 1. The desorption rate $\dot{m}_{\mathrm{d}}$ as a function of the reduced time $\tau=t / t^{*}$. The following values were used for the parameters in Eq. (9): $m_{0}=0.89 \mathrm{~g}, t^{*}=0.190$ sec., $f=0.5, \epsilon=0.43$, $b_{0}=0.193,(1+A)=4.0$, and $t^{*} / t_{\mathrm{d}}=0.01$.

free volume (chamber volume - total apparent volume of beads). For isothermal gases, Eq. (7) may be integrated directly with the result

$$
\begin{array}{r}
\frac{\rho}{\rho_{0}}=\frac{p}{p_{0}}=\exp \left(-\frac{t}{t^{*}}\right)+b_{0}\left[1-\exp \left(-\frac{t}{t^{*}}\right)\right], \\
\text { for } T=T_{0}
\end{array}
$$

where $b_{0}=\nu_{0} t^{*}$ is a constant.

Using Eq. (8) as the boundary condition, the diffusion equation may be solved (see Appendix B for details) for the total rate of mass addition $\dot{m}_{\mathrm{d}}$. The resulting expression for $\dot{m}_{\mathrm{d}}$ is

$$
\begin{gathered}
\dot{m}_{\mathrm{d}}=\left(\frac{m_{0}}{t^{*}}\right)\left[6 \epsilon\left(\frac{1-f}{f}\right)\right]\left(1-b_{0}\right)(1+A)\left(\frac{t^{*}}{t_{\mathrm{d}}}\right) \\
\cdot \sum_{n=1}^{\infty}\left\{\frac{\exp \left(-t / t^{*}\right)-\exp \left[-n^{2} \pi^{2}\left(t^{*} / t_{\mathrm{d}}\right)\left(t / t^{*}\right)\right]}{\left(n^{2} \pi^{2} t^{*} / t_{\mathrm{d}}\right)-1}\right\}
\end{gathered}
$$

where $(1-f) / f$ is equal to $\rho_{0} m_{\mathrm{b}} / \rho_{\mathrm{b}} m_{0}$ if $f$ is the fractional void in the bed, $\rho_{0}$ is the initial density of gases in the chamber, $\rho_{\mathrm{b}}$ is the apparent density of the porous spheres = mass of beads/apparent volume of beads, $m_{\mathrm{b}}$ is the total mass of the beads, $m_{0}=\rho_{0} V$ denotes again the initial mass of free gas in the chamber, $\epsilon$ is the porosity of the beads which is defined as the pore volume divided by the total volume of the beads, $t_{\mathrm{d}}=a^{2} / D$ is a characteristic diffusion time, $a$ is the radius of a single spherical bead, $D=\left(D_{\mathrm{g}}+A D_{\mathrm{a}}\right) /(1+A)$ is an effective diffusion coefficient, $D_{\mathrm{g}}$ and $D_{\mathrm{a}}$ are, respectively, the Knudsen diffusion coefficient and the apparent surface diffusion coefficient, and $A$ is a function of the temperature. Since Eq. (8) fits the experimental results rather well (see Figs. 4, 5, and 6), Eq. (9) should constitute an acceptable expression for $\dot{m}_{\mathrm{d}}$ subject to the assumption of diffusion-controlled desorption. It is apparent that Eq. (9) is consistent with the statements $\dot{m}_{\mathrm{d}}=0$ at $t=0$ and the limit of $\dot{m}_{\mathbf{d}}=0$ as $t \rightarrow \infty$.

A graph of Eq. (9) is shown in Fig. 1 for representative values of the parameters. Reference to Fig. 1 indicates that, to a first approximation, $\dot{m}_{\mathrm{d}}$ may indeed be treated as a constant for $t$ greater than about $\frac{1}{4} t^{*}$.

A second approximation to the pressure in the chamber is obtained by deleting the assumption that $\nu_{0}=\dot{m}_{\mathrm{d}} / m_{0}=$ constant in Eq. (7) and by using instead the relation for $\dot{m}_{\mathrm{d}}$ given in Eq. (9). In this case, Eq. (8) should be replaced by the expression

$$
\begin{aligned}
\frac{\rho}{\rho_{0}}=\frac{p}{p_{0}}=\{1- & {\left[6 \epsilon\left(\frac{1-f}{f}\right)\right]\left(1-b_{0}\right)(1+A)\left(\frac{t^{*}}{t_{\mathrm{d}}}\right) } \\
& \left.\cdot \sum_{n=1}^{\infty}\left[\frac{1-\left[\left(n^{2} \pi^{2} t^{*} / t_{\mathrm{d}}\right)-1\right] t / t^{*}-\exp \left[\left(-n^{2} \pi^{2} t^{*} / t_{\mathrm{d}}\right)+1\right] t / t^{*}}{\left[\left(n^{2} \pi^{2} t^{*} / t_{\mathrm{d}}\right)-1\right]^{2}}\right]\right\} \exp \left(-\frac{t}{t^{*}}\right) .
\end{aligned}
$$

Equation (10) is the first step in obtaining an improved solution to the problem. In the next laborious, though straightforward iteration, Eq. (10) serves as boundary condition in the derivation of an improved expression for $\dot{m}_{\mathrm{d}}$ according to the procedure described in Appendix B.

\section{Adiabatic Conditions and a Constant Rate of Mass Addition in the Chamber}

For the case of adiabatic expansion in the chamber, Eq. (8) should be replaced by the expression

$$
\int_{1}^{p / p_{0}} \frac{d x}{x^{\left(\gamma_{\mathrm{o}}-1\right) / \gamma_{0}}\left[1-\left(1 / \nu_{0} t^{*}\right) x^{\left(\gamma_{\mathrm{c}}+1\right) / 2 \gamma_{\mathrm{c}}}\right]}=\gamma_{\mathrm{c}} \nu_{0} t .
$$

The preceding relation may be integrated for $\gamma_{\mathrm{c}}=\frac{5}{3}$ with the result

$$
\begin{aligned}
& \gamma_{\mathrm{e}} \nu_{0} t=\frac{5}{2} b^{\frac{3}{3}}\left\{\frac{1}{2} \ln \left|\frac{1+x^{1 / 5} b_{0}^{-\frac{1}{4}}}{1-x^{1 / 5} b_{0}^{-\frac{1}{4}}}\right|\left|\frac{1-b_{0}^{-\frac{1}{4}}}{1+b_{0}^{-\frac{1}{4}}}\right|\right. \\
&\left.\quad-\tan ^{-1}\left(x^{1 / 5} b_{0}^{-\frac{1}{4}}\right)+\tan ^{-1}\left(b_{0}^{-\frac{1}{4}}\right)\right\},
\end{aligned}
$$

where $x=p / p_{0}$, and $b_{0}$ is again equal to $\nu_{0} t^{*}$. There is no obvious experimental procedure for realizing near-adiabatic conditions with mass addition.

\section{A More Complete Analysis of Gas Discharge Through a Nozzle From a Two-Phase System}

For a more complete analysis, we must use all of the conservation equations, including the energy 
equation which has been neglected thus far, and obtain a solution after imposition of suitable boundary conditions.

The equation for conservation of mass, using the ideal gas equation of state, has been given in Eq. (7) and may be rewritten in the form

$\frac{d}{d t}\left(\frac{p}{p_{0}}\right)+\frac{p}{p_{0}} \frac{d}{d t} \ln \left(\frac{T_{0}}{T}\right)=\nu \frac{T}{T_{0}}-\frac{1}{t^{*}} \frac{p}{p_{0}}\left(\frac{T}{T_{0}}\right)^{\frac{1}{2}}$,

where $\nu$ is a function of pressure and temperature. An approximate expression for conservation of energy is (see Appendix $\mathrm{C}$ for details)

$$
\frac{d}{d t}\left(m c_{v} T\right)=\dot{Q}+\dot{m}_{\mathrm{d}} c_{p} T_{\mathrm{d}}-\dot{m}_{\mathrm{e}} c_{p} T,
$$

where $m$ represents the total mass of free gas in the chamber, $c_{v}$ and $c_{p}$ denote, respectively, the specific heats of the gas at constant volume and at constant pressure, $\dot{Q}$ is the total rate of energy addition to the gas by heat conduction and radiation, $\dot{m}_{\mathrm{d}}$ is the rate of mass addition of free gas by desorption from the beads at the temperature $T_{\mathrm{d}}$ (we assume that the specific heat of the added gas is the same as that of the chamber gas), and $\dot{m}_{\mathrm{e}}$ represents the mass discharge rate of gases through the nozzle.

Since

$$
\begin{aligned}
m & =p V / R_{\mathrm{g}} T, \\
\dot{m}_{\mathrm{e}} & =\frac{m_{0}}{t^{*}} \frac{p}{p_{0}}\left(\frac{T_{0}}{T}\right)^{\frac{1}{2}},
\end{aligned}
$$

and

$$
\dot{m}_{\mathrm{d}}=\nu m_{0}=\nu p_{0} V / R_{\mathrm{g}} T_{0},
$$

Eq. (12) may be rewritten as

$$
\frac{d}{d t}\left(\frac{p}{p_{0}}\right)=\frac{\dot{Q}}{m_{0} c_{v} T_{0}}+\gamma_{c} \nu \frac{T_{\mathrm{d}}}{T_{0}}-\frac{\gamma_{\mathrm{c}}}{t^{*}} \frac{p}{p_{0}}\left(\frac{T}{T_{0}}\right)^{\frac{1}{2}} .
$$

All of the results derived in the preceding sections may be obtained by starting from Eqs. (11) and (13).

For the isothermal case without mass addition ( $T=T_{0}, \nu=0$ ), Eq. (11) yields

$$
\frac{p}{p_{0}}=\exp \left(-\frac{t}{t^{*}}\right)
$$

which was previously obtained in Eq. (3). In addition, Eq. (13) yields the rate at which heat must be added to the system to maintain $T$ equal to $T_{0}$, viz.,

$$
\frac{\dot{Q}}{m_{0} c_{v} T_{0}}=\frac{1}{t^{*}}\left(\gamma_{c}-1\right) \exp \left(-\frac{t}{t^{*}}\right) .
$$

For the case without heat or mass addition
$(\dot{Q}=0, \nu=0)$, Eqs. (11) and (13) give the following results:

$$
\frac{T}{T_{0}}=\left[1+\frac{1}{2}\left(\gamma_{\mathrm{c}}-1\right) \frac{t}{t^{*}}\right]^{-2},
$$

and

$\frac{p}{p_{0}}=\left[1+\frac{1}{2}\left(\gamma_{\mathrm{c}}-1\right) \frac{t}{t^{*}}\right]^{2 \gamma_{\mathrm{o}} /\left(1-\gamma_{\mathrm{o}}\right)}=\left(\frac{T}{T_{0}}\right)^{\gamma_{\mathrm{c}} /\left(\gamma_{\mathrm{o}}-1\right)}$.

The first equality in Eq. (16) was obtained previously in Eq. (6) for adiabatic expansion.

For the isothermal case with a constant rate of mass addition $\left(T=T_{0}, \nu=\nu_{0}=\right.$ constant), Eq. (11) yields

$$
\frac{p}{p_{0}}=\exp \left(-\frac{t}{t^{*}}\right)+\nu_{0} t^{*}\left[1-\exp \left(-\frac{t}{t^{*}}\right)\right]
$$

which was previously obtained in Eq. (8). Equation (13) may be used to obtain again the rate of heat addition necessary to maintain $T=T_{\mathbf{d}}=T_{0}$. The result is

$$
\frac{\dot{Q}}{m_{0} c_{v} T_{0}}=\frac{1}{t^{*}}\left(\gamma_{\mathrm{c}}-1\right)\left(1-b_{0}\right) \exp \left(-\frac{t}{t^{*}}\right) .
$$

In the general case where both heat and mass addition occur, it is necessary to specify both $\dot{Q}$ and $\dot{m}_{\mathrm{d}}$ explicitly and then to solve the resulting coupled relations, viz., Eqs. (11) and (13). We shall not pursue this approach further since acceptable fits are obtained to the experimental data on the assumption that isothermal flow with a constant rate of mass addition occurs.

\section{EXPERIMENTAL PROCEDURE AND RESULTS}

We shall now describe the experimental procedure for the determination of chamber pressure as a function of time, show how these measurements may be used to obtain desorption rates, and finally interpret the observed data in terms of the previously derived theoretical expressions.

\section{A. Experimental Procedure}

A schematic diagram of the apparatus used is shown in Fig. 2. The apparatus consisted of a reaction vessel with a volume of $1110 \mathrm{~cm}^{3}$ (1) which contained the gas and the solid particles, a de Laval nozzle (2) with a throat diameter of $4.4 \mathrm{~mm}$, a rapidly opening ${ }^{5}$ valve (3), and a dump tank (4). The dump tank, the volume of which was ten times that of the reaction vessel, was evacuated to a pressure much lower than the chamber pressure (the initial

\footnotetext{
${ }^{5}$ H. H. Heitland, Rev. Sci. Instr. 32, 1203 (1961).
} 


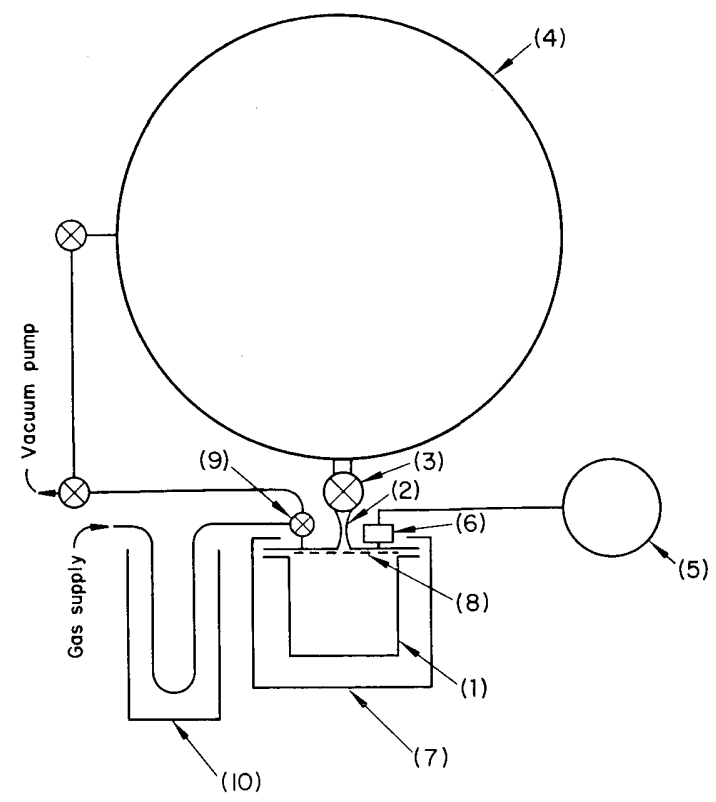

FIG. 2. Schematic diagram showing the apparatus used for experimental measurements; (1) reaction vessel; (2) de Laval nozzle; (3) rapidly opening valve; (4) dump tank; (5) oscilloscope; (6) strain-gage pressure transducer; (7) heating or cooling bath; (8) 100-mesh screen; (9) three-way stopcock; (10) dry ice trap for removal of water.

pressures in the dump tank and in the reaction vessel were about $0.5 \mathrm{~mm}$ of $\mathrm{Hg}$ and about 740 $\mathrm{mm} \mathrm{Hg}$, respectively). The valve at the nozzle exist position opened in less than $10^{-3} \mathrm{sec}$ and pseudosteady discharge of gas from the reaction vessel began in about one millisec. An oscilloscope (5), equipped with a camera, was used to record the time dependence of the pressure as measured by a strain-gage pressure transducer (6) installed in the reaction vessel. The temperature of the contents of the reaction vessel was regulated by using either a heating mantel or an acetone-dry ice cooling bath (7). Five iron-constantan thermocouples were used to record the temperature of the gas in the reaction vessel. The top of the reaction vessel could be removed to allow introduction of solid particles. A 100-mesh screen (8) was located upstream of the de Laval nozzle to prevent solid particles from being blown into the nozzle. The reaction vessel was evacuated and filled with gas by means of a threeway stopcock (9). The gas was passed through a dry ice-water trap (10) before entering the reaction vessel.

For each gas $\left(\mathrm{CO}_{2}, \mathrm{Ar}\right.$, and $\left.\mathrm{He}\right)$, the chamber pressure was measured as a function of time for (a) initial temperatures ranging from $-50^{\circ}$ to $120^{\circ} \mathrm{C}$ with the chamber filled with $6-16$ mesh silica gel, (b) an initial temperature of about $22^{\circ} \mathrm{C}$ with the chamber filled with 12-mesh quartz sand, and (c) an initial temperature of about $22^{\circ} \mathrm{C}$ with the chamber empty. The same material, consisting of $696 \mathrm{~g}$ of 6-16 mesh silica gel, was used in all of the experiments performed under (a); in the experiments (b), a sample of $1331 \mathrm{~g}$ of 12-mesh quartz sand was used.

The system containing silica gel was prepared for a series of experiments with each of the adsorbed gases by heating the reaction vessel and its contents to about $130^{\circ} \mathrm{C}$, evacuating and flushing the system with the gas, and finally allowing the system to reach equilibrium at a pressure of about one atmossphere and at a temperature of about $120^{\circ} \mathrm{C}$. The first measurement of pressure as a function of time was made at about $120^{\circ} \mathrm{C}$, and succeeding measurements were made at successively reduced temperatures using intervals of $15^{\circ}$ to $20^{\circ} \mathrm{C}$ down to about $-50^{\circ} \mathrm{C}$.

The system with quartz sand was thoroughly evacuated and then flushed with each of the gases used before performing an experiment.

\section{B. Experimental Determination of Desorption Rates}

Since the calculations given in Appendix A, as well as the experimental measurements of chamber temperature, indicate that the free chamber gases are nearly isothermal for $t>0$, Eq. (11) may be used with $T=T_{0}$ and $d\left(T / T_{0}\right) / d t=0$ for the direct determination of $b=\dot{m}_{\mathrm{d}} t^{*} / m_{0}=\nu_{0} t^{*}$. Thus $b$ may be derived from the experimental data of pressure as a function of time by using the expression

$$
b(\tau)=\frac{p}{p_{0}}+\frac{d}{d \tau}\left(\frac{p}{p_{0}}\right)
$$

where $\tau=t / t^{*}$.

\section{Experimental Results for Empty Chambers and for Chambers Containing Sand}

The results of an extensive series of experimental measurements are described in reference 6 . For discharge from a vessel without solid particles, the theoretical estimates of $\gamma_{\mathrm{c}}=\gamma$ for $\mathrm{CO}_{2}, \mathrm{Ar}$, and $\mathrm{He}$ apply very closely, at least during the initial phases of the experiments. For $\tau$ greater than about 0.6 , heat transfer was found to affect the chamber pressure somewhat for $\mathrm{Ar}$ and $\mathrm{He}$. For $\mathrm{CO}_{2}$, the influence of heat transfer was offset by an increase in $\gamma$ during the discharge (heat transfer tends to increase the pressure whereas cooling tends to increase in $\gamma$ ). As the result of fortuitous compensation, a very close fit was obtained to the theoretical equation for

${ }^{6}$ J. W. Porter, Ph.D. Thesis, California Institute of Technology, 1963. 


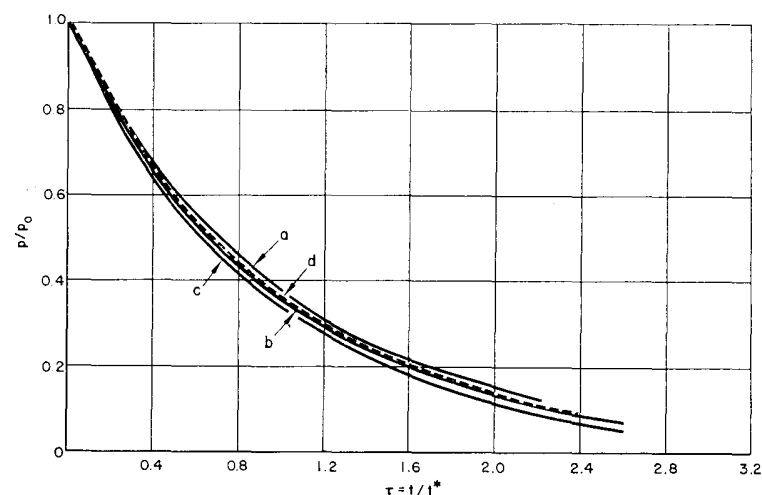

FIG. 3. The reduced pressure $p / p_{0}$ as a function of the reduced time $\tau=t / t^{*}$ for $\mathrm{CO}_{2}, \mathrm{Ar}$, and $\mathrm{He}$ discharging from a vessel containing 12-mesh quartz sand. a: Experimental curve for He with $t^{*}=0.069$ and $p_{0}=743 \mathrm{~mm} \mathrm{Hg}$; initial temperature $T_{0}=24^{\circ} \mathrm{C}$. b: Experimental curve for $\mathrm{CO}_{2}$ with $t^{*}=0.250$ and $p_{0}=741 \mathrm{~mm} \mathrm{Hg}$; initial temperature $T_{0}=23^{\circ} \mathrm{C}$. c: Experimental curve for Ar with $t^{*}=0.219$ and $p_{0}=744 \mathrm{~mm} \mathrm{Hg}$; initial temperature $T_{0}=24^{\circ} \mathrm{C}$. $\mathrm{d}$ : Theoretical curve for an isothermal system without mass addition.

adiabatic expansion for $\mathrm{CO}_{2}$ and $\tau \leq 2.2$ with $\gamma_{\mathrm{c}}=$ $1.34, t^{*}=0.465, T_{0}=22^{\circ} \mathrm{C}, p_{0}=745 \mathrm{~mm} \mathrm{Hg}$.

The results shown in Fig. 3 refer to the discharge of $\mathrm{CO}_{2}, \mathrm{Ar}$, and $\mathrm{He}$ when the vessel contains 12mesh quartz sand with a measured density of $2.6 \mathrm{~g} / \mathrm{cm}^{3}$. The broken curve represents the theoretical equation (with $t^{*}$ computed for the appropriate value of $\gamma$ at $T_{0}$ ) for an isothermal system without mass addition. The relatively small differences between the experimental curves for the different gases indicate that very little mass addition by desorption occurred during the experiments. Furthermore, the close agreement of the experimental curves with the theoretical curve for isothermal gases indicates that nearly isothermal conditions existed in the chamber during the discharge.

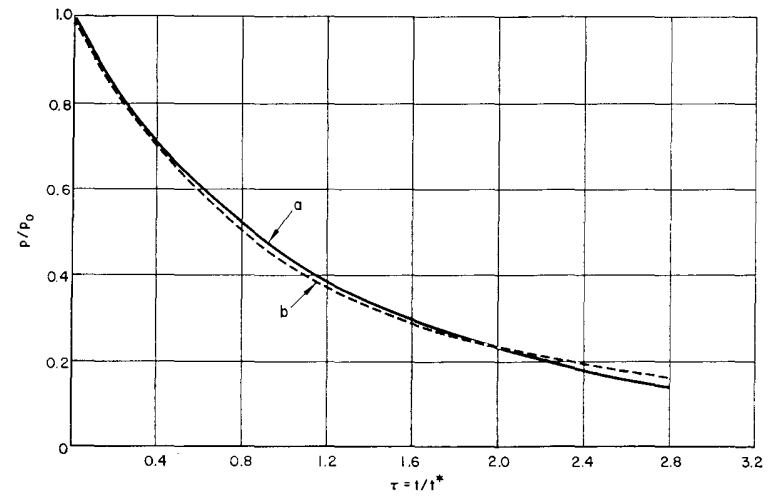

FIG. 4. The reduced pressure $p / p_{0}$ as a function of the reduced time $\tau=t / t^{*}$ for $\mathrm{He}$ discharging from a vessel containing silica gel of mesh size 6-16. a: Experimental curve for $t^{*}=0.053 \mathrm{sec}$ and $p_{0}=746 \mathrm{~mm} \mathrm{Hg}$; initial temperature $T_{0}=114^{\circ} \mathrm{C}$. b: Calculated curve using Eq. (8) with $b_{0}=0.105$.

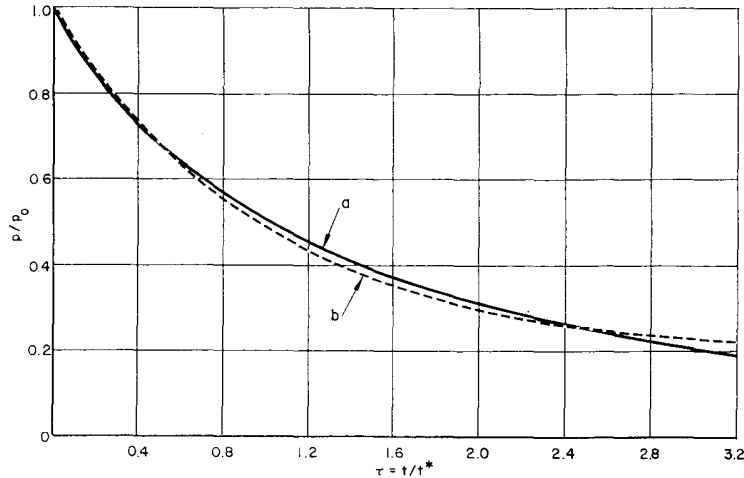

Fig. 5. The reduced pressure $p / p_{0}$ as a function of the reduced time $\tau=t / t^{*}$ for Ar discharging from a vessel containing silica gel of mesh size 6-16. a: Experimental curve for $t^{*}=0.193 \mathrm{sec}$ and $p_{0}=745 \mathrm{~mm} \mathrm{Hg}$; initial temperature $T_{0}=15^{\circ} \mathrm{C}$. b: Calculated curve using Eq. (8) with $b_{0}=0.189$.

\section{Experimental Results for Chambers Containing 6-16 Mesh Silica Gel}

Representative experimental data (solid curves) for the reduced pressure as a function of the reduced time are shown in Figs. 4 to 6 for $\mathrm{He}, \mathrm{Ar}$, and $\mathrm{CO}_{2}$, respectively, together with least-square fits calculated (dashed curves) according to Eq. (8). The values of $t^{*}$ were computed according to Eq. (4) by using for $\gamma$ the calculated value for the gas at $T=T_{0}$. The constants $b_{0}$, which were determined from fits to the experimentally determined $p / p_{0}$ vs $\tau$ curves of the type shown in Figs. 4 to 6 , are summarized in Fig. 7 as a function of the initial temperature $T_{0}$ for the $\mathrm{CO}_{2}-$, Ar-, and $\mathrm{He}$-silica gel systems. It is apparent that the empirically determined values of $b_{0}=\nu_{0} t^{*}$, together with the calculated values of $t^{*}$, provide an estimate for the characteristic desorption frequency $\nu_{0}$. The value of the free chamber volume $V$ used in Eq. (4) for

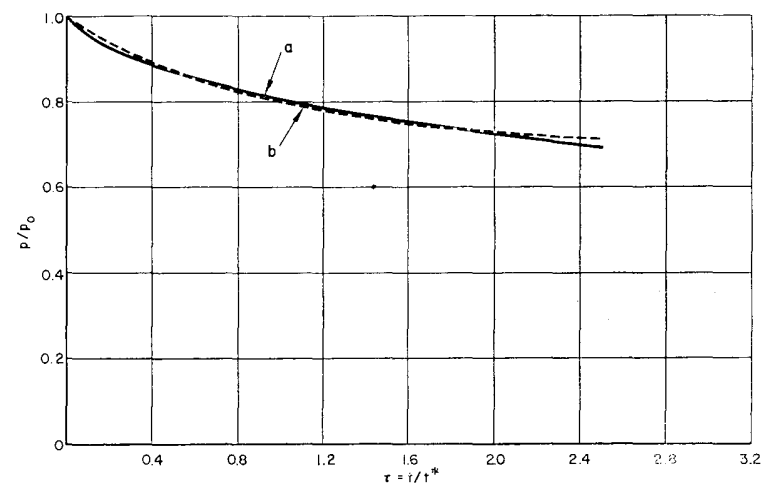

FIG. 6. The reduced pressure $p / p_{0}$ as a function of the reduced time $\tau=t / t^{*}$ for $\mathrm{CO}_{2}$ discharging from a vessel containing silica gel of mesh size 6-16. a: Experimental curve for $t^{*}=0.242 \mathrm{sec}$ and $p_{0}=756 \mathrm{~mm} \mathrm{Hg}$; initial temperature $T_{0}=-36^{\circ} \mathrm{C}$. b: Calculated curve using Eq. (8) with $b_{0}=0.684$. 


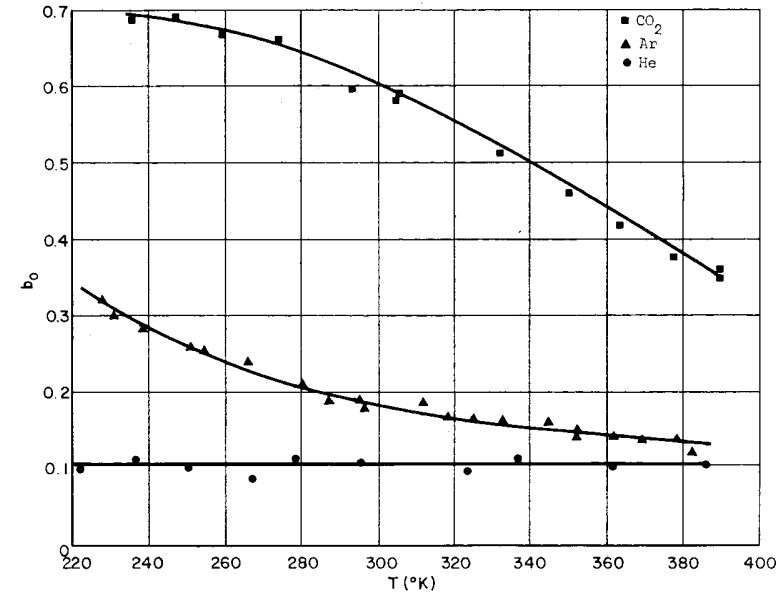

FIG. 7. The parameter $b_{0}$ [see Eq. (8)] as a function of temperature for $\mathrm{CO}_{2}, \mathrm{Ar}$, and $\mathrm{He}$ discharging from a vessel containing silica gel of mesh size 6-16.

the evaluation of $t^{*}$ was determined by taking the difference between the volume of the reaction vessel and the volume of the beads. The volume of the beads includes the pore volume and corresponds to the ratio $m_{\mathrm{b}} / \rho_{\mathrm{b}}$ where $m_{\mathrm{b}}$ is the total mass of the beads; the density $\rho_{\mathrm{b}}$ for silica gel was supplied by the manufacturer as 1.2 to $1.3 \mathrm{~g} / \mathrm{cm}^{3}$. As is to be expected, the reduced desorption rates increase as the temperatures are reduced because larger amounts of gas are initially adsorbed at lower temperatures, at least for $\mathrm{CO}_{2}$ and $\mathrm{Ar}$.

Representative experimental curves of $b(\tau)$, as determined from Eq. (18) for $\mathrm{CO}_{2}$ and $\mathrm{Ar}$ at various temperatures, are shown in Fig. 8. The similarity

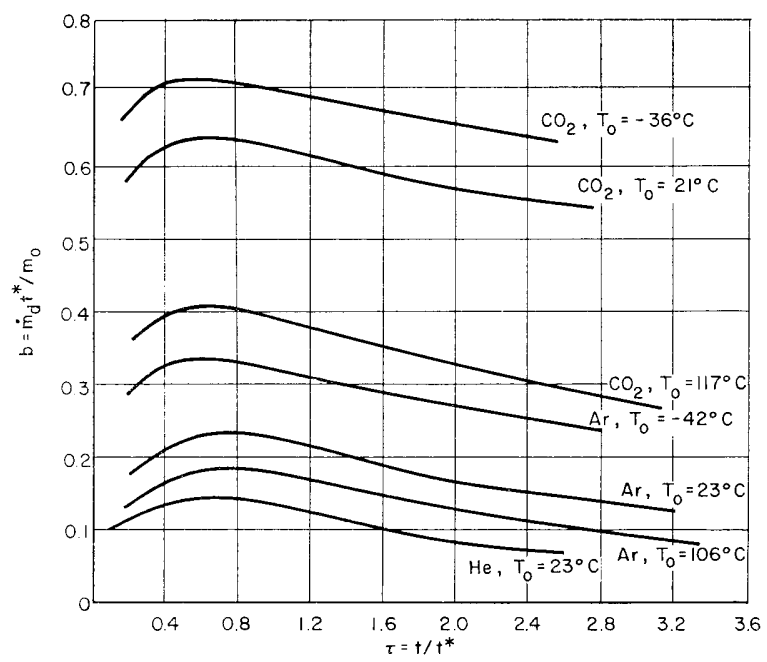

FIG. 8. Representative experimental curves showing the dimensionless desorption rate $b=\dot{m}_{\mathrm{d}} t^{*} / m_{0}$ as a function of the reduced time $\tau=t / t^{*}$ for gases discharging from a vessel containing silica gel of mesh size 6-16.

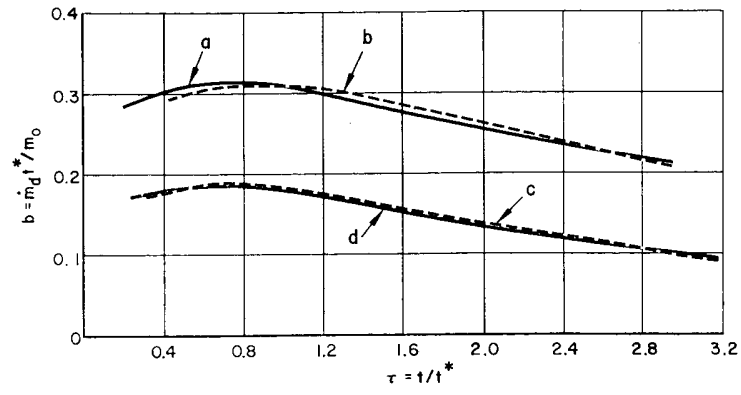

FIG. 9. The dimensionless desorption rate $b=\dot{m}_{\mathrm{d}} t^{*} / m_{0}$ as a function of the reduced time $r=t / t^{*}$ for Ar discharging from a vessel containing silica gel of mesh size $6-16$. a: Experimental curve for $t^{*}=0.212$ sec and $p_{0}=740 \mathrm{~mm} \mathrm{Hg}$; initial temperature $T_{0}=-34^{\circ} \mathrm{C}$. b: Theoretical curve calculated by using Eq. (9) with $t^{*} / t_{\mathrm{d}}=0.0002,(1+A)=41$, $\left(1-b_{0}\right)=0.72$, and $6 \epsilon(1-f) / f=2.6$. $c$ : Theoretical curve calculated by using Eq. (9) with $t^{*} / t_{\mathrm{d}}=0.02,(1+A)=2.3$, $\left(1-b_{0}\right)=0.85$, and $6 \epsilon(1-f) / f=2.6$. d: Experimental curve for $t^{*}=0.168 \mathrm{sec}$ and $p_{0}=744 \mathrm{~mm} \mathrm{Hg}$; initial temperature $T_{0}=105^{\circ} \mathrm{C}$.

between the shapes of these curves and the curve plotted in Fig. 1 is noteworthy. The theoretical relation [see Eq. (9)] for $b(\tau)=\dot{m}_{\mathrm{d}} t^{*} / m_{0}$ may be fitted to each of the experimental curves of $b(\tau)$. This fit is accomplished by choosing suitable values of the parameter $\alpha=t^{*} / t_{\mathrm{d}}$ and of the factor $[6 \epsilon(1-f) / f]\left(1-b_{0}\right)(1+A)$. For $\mathrm{Ar}$ and $\mathrm{He}$, the theoretical curves of $b(\tau)$ fit the experimental curves very closely for all $\tau$, and both $\alpha$ and $[6 \epsilon(1-f) / f]\left(1-b_{0}\right)(1+A)$ are, therefore, determined as functions of the temperature. Figures 9 and 10 show theoretical curves of $b(\tau)$ fitted to representative experimental curves for $\mathrm{Ar}$ and $\mathrm{He}$, respectively.

For $\mathrm{CO}_{2}$, the experimental curves were best fitted by using the limiting form of Eq. (9) for small values of $\alpha$ [see Eq. (B21)]. However, the fits were not very good, particularly at the lower

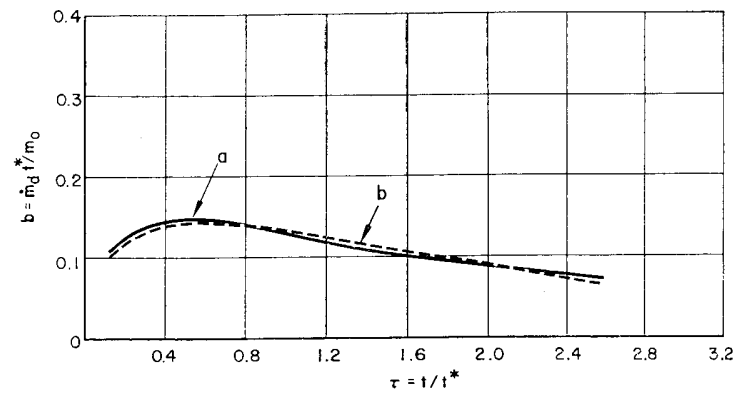

FIG. 10. The dimensionless desorption rate $b=\dot{m}_{\mathrm{d}} t^{*} / m_{0}$ as a function of the reduced time $\tau=t / t^{*}$ for He discharging from a vessel containing silica gel of mesh size $6-16$. a: Experimental curve for $t^{*}=0.060$ sec and $p_{0}=747 \mathrm{~mm} \mathrm{Hg}$; initial temperature $T_{0}=23^{\circ} \mathrm{C}$. b: Theoretical curve calculated by using Eq. (9) with $t^{*} / t_{\mathrm{d}}=0.058,(1+A)=1.1,\left(1-b_{0}\right)=$ 0.89 , and $6 \epsilon(1-f) / f=2.6$. 
Table I. Values for He of the parameters $b_{0}, \alpha=t^{*} / t_{\mathrm{d}}$, and $(1+A)$ obtained by fitting Eqs. (8) and (9) to the experimental data; also listed are estimates for $\left(D_{\mathrm{g}}+A D_{\mathrm{a}}\right)$ and $\left(D_{\mathrm{g}}\right)_{\text {theor. }}$

\begin{tabular}{cccccc}
\hline $\mathrm{T}\left({ }^{\circ} \mathrm{K}\right)$ & $b_{0}$ & $\alpha \times 10^{2}$ & $(1+A)$ & $\begin{array}{c}\left(D_{\mathrm{g}}+A D_{\mathrm{a}}\right) \times 10^{3} \\
\left(\mathrm{~cm}^{2} / \mathrm{sec}\right)\end{array}$ & $\begin{array}{c}\left(D_{\mathrm{g}}\right)_{\text {theor }} \times 10^{3} \\
\left(\mathrm{~cm}^{2} / \mathrm{sec}\right)\end{array}$ \\
\hline 223 & 0.095 & 8.0 & 0.7 & 12.2 & 14.5 \\
237 & 0.112 & 5.0 & 1.0 & 11.2 & 15.0 \\
251 & 0.103 & 5.0 & 1.0 & 11.0 & 15.4 \\
268 & 0.088 & 9.0 & 0.7 & 14.4 & 16.2 \\
279 & 0.114 & 5.0 & 1.0 & 12.1 & 16.7 \\
296 & 0.110 & 5.8 & 1.1 & 14.5 & 17.8 \\
324 & 0.099 & 8.0 & 0.8 & 16.1 & 18.5 \\
337 & 0.112 & 6.0 & 1.0 & 15.7 & 19.1 \\
362 & 0.105 & 6.0 & 0.9 & 14.8 & 13.6 \\
389 & 0.105 & 5.0 & 1.0 & & \\
\hline \hline
\end{tabular}

TABLE II. Values for Ar of the parameters $b_{0}, \alpha=t^{*} / t_{\mathrm{d}}$, and $(1+A)$ obtained by fitting Eqs. (8) and $(9)$ to the experimental data; also listed are estimates for $\left(D_{\mathrm{g}}+A D_{\mathrm{a}}\right)$ and $\left(D_{\mathrm{g}}\right)_{\mathrm{theor}}$.

\begin{tabular}{cccccc}
\hline \hline$T\left({ }^{\circ} \mathrm{K}\right)$ & & & & $\left(D_{\mathrm{g}}+\begin{array}{c}\left.A D_{\mathrm{a}}\right) \times 10^{3} \\
\left(\mathrm{~cm}^{2} / \mathrm{sec}\right)\end{array}\right.$ & $\begin{array}{c}\left(D_{\mathrm{g}}\right)_{\text {theor }} \times 10^{3} \\
\left(\mathrm{~cm}^{2} / \mathrm{sec}\right)\end{array}$ \\
\hline & $b_{0}$ & $\alpha \times 10^{3}$ & $(1+A)$ & \\
228 & 0.324 & 0.2 & 50 & 0.7 & 4.6 \\
231 & 0.296 & 0.2 & 43 & 0.6 & 4.7 \\
251 & 0.280 & 0.2 & 41 & 0.6 & 4.7 \\
255 & 0.259 & 1.0 & 17 & 1.2 & 4.9 \\
267 & 0.254 & 1.0 & 16 & 1.1 & 5.0 \\
267 & 0.240 & 2.0 & 11 & 1.6 & 5.0 \\
281 & 0.239 & 1.2 & 14 & 1.2 & 5.1 \\
288 & 0.211 & 7.0 & 5.3 & 2.7 & 5.2 \\
296 & 0.189 & 12.0 & 3.8 & 3.4 & 5.3 \\
296 & 0.187 & 10.0 & 3.9 & 3.0 & 5.3 \\
297 & 0.193 & 10.0 & 4.0 & 3.0 & 5.4 \\
312 & 0.179 & 12.0 & 3.4 & 3.0 & 5.5 \\
319 & 0.189 & 6.0 & 5.0 & 2.4 & 5.5 \\
319 & 0.172 & 20.0 & 2.8 & 4.3 & 5.5 \\
325 & 0.169 & 20.0 & 2.6 & 4.0 & 5.6 \\
333 & 0.170 & 20.0 & 2.6 & 4.1 & 5.6 \\
334 & 0.165 & 20.0 & 2.6 & 4.1 & 5.7 \\
345 & 0.161 & 18.0 & 2.6 & 3.8 & 5.8 \\
353 & 0.162 & 20.0 & 2.5 & 4.1 & 5.8 \\
353 & 0.152 & 20.0 & 2.3 & 3.9 & 5.9 \\
363 & 0.142 & 20.0 & 2.2 & 3.6 & 5.9 \\
370 & 0.143 & 20.0 & 2.1 & 3.6 & 6.0 \\
378 & 0.142 & 20.0 & 2.2 & 3.7 & 6.0 \\
379 & 0.147 & 20.0 & 2.3 & 3.9 & 6.0 \\
383 & 0.142 & 24.0 & 2.0 & 4.0 & \\
& 0.124 & 28.0 & 1.6 & 4.0 & \\
\hline \hline
\end{tabular}

temperatures. Furthermore, only the product $6 \epsilon[(1-f) / f]\left(1-b_{0}\right)(1+A) \alpha^{\frac{1}{2}}$ is determined by using this procedure. Figure 11 shows the theoretical curves of $b(\tau)$ fitted to representative experimental curves of $b(\tau)$ for $\mathrm{CO}_{2}$.

The dependence of $b_{0}$ on temperature for the $\mathrm{CO}_{2}-$, Ar-, and He-silica gel systems has been shown previously (in Fig. 7) and the factor $6 \epsilon(1-f) / f$ is a known constant which was the same in all of the experiments; hence, for $\mathrm{Ar}$ and $\mathrm{He}$, it was possible to determine $\alpha$ and $(1+A)$ as functions of temperature (see Tables I and II); on the other hand, for $\mathrm{CO}_{2}$, only the product $\alpha^{\frac{1}{2}}(1+A)$ was determined as a function of temperature (see Table III).
TABle III. Values for $\mathrm{CO}_{2}$ of the parameters $b_{0}$ and $\alpha^{1 / 2}(1+A)$ obtained by fitting Eqs. (9) and (B21) to the experimental data.

\begin{tabular}{ccc}
\hline \hline$T\left({ }^{\circ} \mathrm{K}\right)$ & $b_{0}$ & $\alpha^{\mathrm{t}}(1+A)$ \\
\hline 237 & 0.684 & 3.0 \\
248 & 0.692 & 3.1 \\
260 & 0.669 & 2.9 \\
274 & 0.660 & 2.8 \\
294 & 0.600 & 2.1 \\
305 & 0.584 & 2.1 \\
306 & 0.593 & 2.0 \\
333 & 0.515 & 1.5 \\
351 & 0.461 & 1.2 \\
364 & 0.423 & 1.1 \\
378 & 0.379 & 0.9 \\
390 & 0.356 & 0.8 \\
390 & 0.367 & 0.8 \\
\hline \hline
\end{tabular}




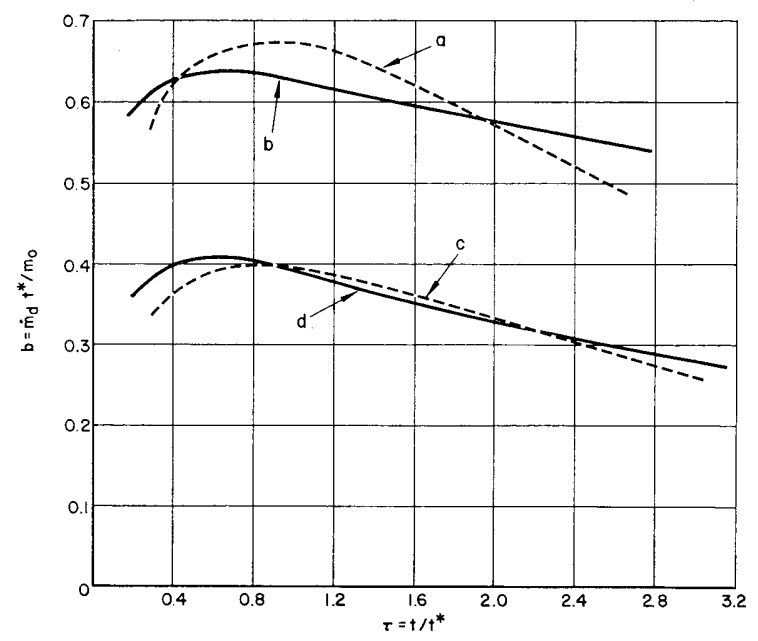

FIG. 11. The dimensionless desorption rate $b=\dot{m}_{\mathrm{d}} t^{*} / m_{0}$ as a function of the reduced time $\tau=t / t^{*}$ for $\mathrm{CO}_{2}$ discharging from a vessel containing silica gel of mesh size 6-16. a: Theoretical curve calculated by using Eq. (B21) with $\left(t^{*} / t_{\mathrm{d}}\right)^{\frac{t}{2}}(1+A)=2.1,\left(1-b_{0}\right)=0.40$, and $6 \epsilon(1-f) / f=2.6$. $\mathrm{b}$ : Experimental curve for $t^{*}=0.219$ sec and $p_{0}=746 \mathrm{~mm} \mathrm{Hg}$; initial temperature $T_{0}=21^{\circ} \mathrm{C}$. c: Theoretical curve calculated by using Eq. (B21) with $\left(t^{*} / t_{\mathrm{d}}\right)^{\frac{1}{*}}(1+A)=0.8$, $\left(1-b_{0}\right)=0.64$, and $6 \epsilon(1-f) / f=2.6$. d: Experimental curve for $t^{*}=0.192 \mathrm{sec}$ and $p_{0}=738 \mathrm{~mm} \mathrm{Hg}$; initial temperature $T_{0}=117^{\circ} \mathrm{C}$.

\section{DISCUSSION OF DESORPTION RATE MEASUREMENTS}

\section{A. Results Obtained for $\mathrm{He}$}

The values of $\alpha$ and $(1+A)$ obtained by fitting the theoretical equation for the dimensionless desorption rate $b(\tau)$ to the experimental curves of $b(\tau)$ for $\mathrm{He}$ are shown in Table I. Earlier experiments by other investigators indicate that $\mathrm{He}$ is not measurably adsorbed (i.e., $A \simeq 0$ ) except at very low temperatures. ${ }^{7,8}$ For $A=0$, the quantity

$$
\alpha=t^{*}\left(D_{\mathrm{g}}+A D_{\mathrm{a}}\right) / a^{2}(1+A)
$$

becomes

$$
\alpha=t^{*} D_{\mathrm{g}} / a^{2}
$$

which is independent of the temperature since $t^{*} \propto T^{-\frac{1}{2}}$ and $D_{\mathrm{g}} \propto T^{\frac{1}{2}}$. Our experimental values for $\alpha$ and $A$ for He (see Table I) agree with these findings, within the limits of experimental error. The percentage error in the quantity $(1+A)$ for $\mathrm{He}$ is estimated to be about $\pm 15 \%$. In addition, the experimental results indicate that $\alpha$ is nearly independent of temperature. The experimental values of $\alpha$ and of $(1+A)$ have been used in Eq. (19) to obtain the quantity $\left(D_{\mathrm{g}}+A D_{\mathrm{a}}\right)$. Theoretical values of the Knudsen diffusion coefficient $\left(D_{\mathrm{g}}\right)_{\text {theor }}$ (see Appendix B) were calculated for each experi-

\footnotetext{
${ }^{7}$ I. F. Homfray, Z. Phys. Chem. 74, 129 (1910).

${ }^{8}$ Reference 2, p. 382.
}

ment. Both $\left(D_{\mathrm{g}}+A D_{\mathrm{a}}\right)$ and $\left(D_{\mathrm{g}}\right)_{\text {theor }}$ are listed in Table I. Within the limits of experimental error, we obtain the result

$$
D_{\mathrm{g}}+A D_{\mathrm{a}} \simeq\left(D_{\mathrm{g}}\right)_{\mathrm{theor}} .
$$

The percentage error in the experimental value of $\left(D_{\mathrm{g}}+A D_{\mathrm{a}}\right)$ is at least as great as the $\pm 15 \%$ error in $(1+A)$, and the percentage error in $\left(D_{\mathrm{g}}\right)_{\text {theor }}$ is estimated to be about $\pm 25 \%$ (because of uncertainty in the value of the pore radius $a_{\mathrm{p}}$ ).

\section{B. Results Obtained for Ar}

The results for Ar listed in Table II indicate that both $\alpha$ and $A$ are functions of the temperature. Assuming that $A \propto \exp (Q / R T)$, where $Q$ is the molar heat of adsorption, a plot of $\ln A$ as a function of $1 / T$ should yield a straight line with slope $Q / R$ if $Q$ is constant. The plot of $\ln A$ as a function of $1 / T$ for $\mathrm{Ar}$ is shown in Fig. 12. The slope of the solid line through the empirically determined points yields $Q \simeq 4200 \mathrm{cal} / \mathrm{mole}$. The literature value for the molar heat of adsorption of $\mathrm{Ar}$ on silica gel is about $3000 \mathrm{cal} / \mathrm{mole}^{9}$

The quantity $\left(D_{\mathrm{g}}+A D_{\mathrm{a}}\right)$ for Ar has been calculated by using Eq. (19) together with the experimentally determined values of $\alpha$ and $(1+A)$. It has been found to be smaller than the theoretical values of the Knudsen diffusion coefficient $\left(D_{\mathrm{g}}\right)_{\text {theor }}$ for Ar, which have been calculated by using for $D_{\mathrm{g}}$ the equation given in Appendix B. Both $\left(D_{\mathrm{g}}+A D_{\mathrm{a}}\right)$ and $\left(D_{\mathrm{g}}\right)_{\text {theor }}$ are listed in Table II. As the temperature is decreased, the values of $\left(D_{\mathrm{g}}+A D_{\mathrm{a}}\right)$ begin to decrease rapidly, compared to $\left(D_{\mathrm{g}}\right)_{\mathrm{theor}}$,

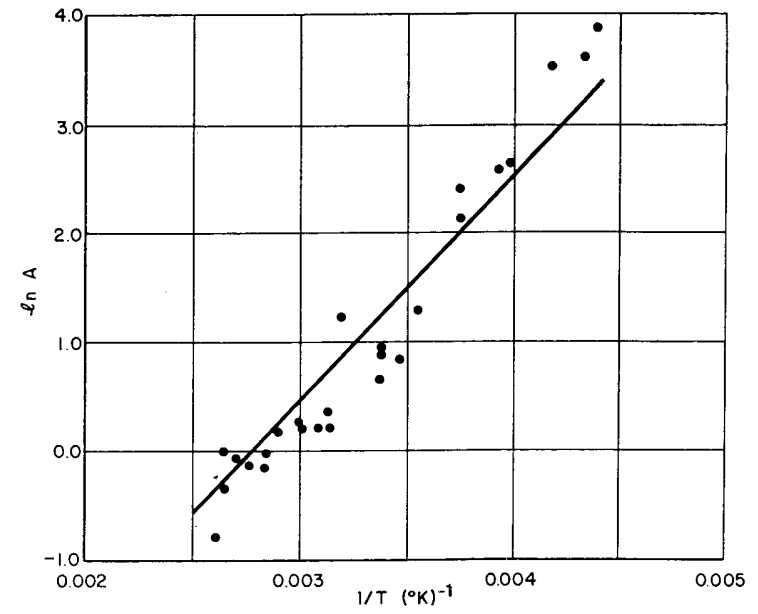

FIG. 12. The logarithm of $A$ as a function of the reciprocal temperature $1 / T$ for Ar.

${ }^{9}$ W. Kälberer and C. Schuster, Z. Phys. Chem. A141, 270 (1929) 
in the neighborhood of $T=280^{\circ} \mathrm{K}$. This change, as well as the relatively small numerical values of $\left(D_{\mathrm{g}}+A D_{\mathrm{a}}\right)$, may possibly be explained by assuming that the porosity of the silica gel, $\epsilon$, is effectively reduced because of the volume occupied by the adsorbed molecules. For example, the cross sectional area of a pore with a radius of $20 \AA$ is reduced by a factor of 0.64 due to a single adsorbed layer of molecules with collision diameters approximately equal to $4 \AA$. Since $(1+A)$ is proportional to $1 / \epsilon$, $\left(D_{\mathrm{g}}+A D_{\mathrm{a}}\right)$ is also proportional to $1 / \epsilon$ [see Eq. (19)]. Therefore, a reduction in $\epsilon$ as the temperature decreases (i.e., as the amount of adsorption increases) would result in larger values for $\left(D_{\mathrm{g}}+A D_{\mathrm{a}}\right)$ than those which were obtained in Table II on the assumption that the value of $\epsilon$ is constant.

\section{Results Obtained for $\mathrm{CO}_{2}$}

As was indicated in Sec. IIID, only the product $\alpha^{\frac{1}{2}}(1+A)$ is determined experimentally for $\mathrm{CO}_{2}$. In references 9 and 10 it is shown that the value of $A$ for $\mathrm{CO}_{2}$ at $150^{\circ} \mathrm{C}$ is approximately the same as the value of $\mathrm{A}$ for $\mathrm{Ar}$ at $-22^{\circ} \mathrm{C}$; the experimental results listed for Ar in Table II show that $A \simeq 16$ at $T_{0} \simeq-22^{\circ} \mathrm{C}$; hence, we may assume that $A \gg 1$ for $\mathrm{CO}_{2}$ in the temperature range from $-50^{\circ}$ to $120^{\circ} \mathrm{C}$. Using Eq. (19), the product $\alpha^{\frac{1}{2}}(1+A)$ may be written as

$$
\alpha^{\frac{1}{2}}(1+A)=\left[t^{*}(1+A)\left(D_{\underline{\underline{g}}}+A D_{\mathfrak{a}}\right) / a^{2}\right]^{\frac{1}{2}}
$$

or, for $A \gg 1$,

$$
\alpha^{\frac{1}{2}}(1+A) \simeq\left[t^{*} A\left(D_{\mathrm{g}}+A D_{\mathrm{a}}\right) / a^{2}\right]^{\frac{1}{2}} .
$$

Assuming that $D_{\mathrm{g}} \ll A D_{\mathrm{a}}$, Eq. (21) becomes

$$
\alpha^{\frac{1}{2}}(1+A) \simeq A\left(t^{*} D_{\mathrm{a}} / a^{2}\right)^{\frac{1}{2}} .
$$

Substituting $D_{\mathrm{a}}=$ (constant) $T^{\frac{1}{2}} \exp (-E / R T){ }^{11}$ where $E$ is the molar activation energy for surface diffusion, and $A=$ (constant) $\exp (Q / R T)$ into Eq. (22) yields the following temperature dependence for $\alpha^{\frac{1}{2}}(1+A)$ :

$$
\alpha^{\frac{1}{2}}(1+A) \propto \exp \left[Q-\frac{1}{2} E\right] / R T .
$$

Therefore, a graph of $\ln \left[\alpha^{\frac{1}{2}}(1+A)\right]$ as a function of $1 / T$ should yield a straight line with slope $\left[Q-\frac{1}{2} E\right] / R$.

Assuming, on the other hand, that $D_{\mathrm{g}} \gg A D_{\mathrm{a}}$, Eq. (21) reduces to

$$
\alpha^{\frac{1}{2}}(1+A) \simeq\left(t^{*} A D_{\mathrm{g}} / a^{2}\right)^{\frac{1}{2}} .
$$

${ }^{10} \mathrm{~W}$. Kälberer and H. Mark, Z. Phys. Chem. A139, 151 (1928).

${ }_{11}$ P. C. Carman, Flow of Gases Through Porous Media (Academic Press Inc., New York, 1956), p. 120.

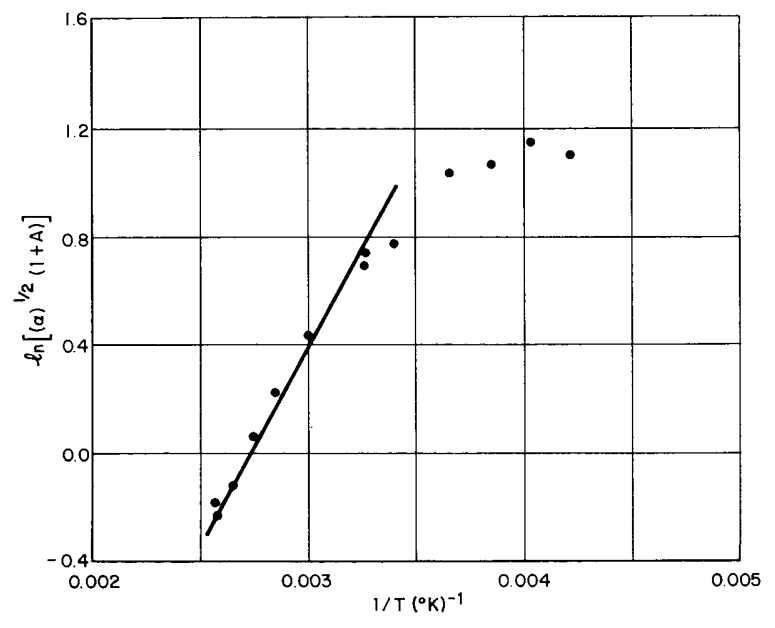

FIg. 13. The logarithm of $\alpha^{\frac{1}{2}}(1+A)$ as a function of the reciprocal temperature $1 / T$ for $\mathrm{CO}_{2}$.

Again substituting $A=$ (constant) $\exp (Q / R T)$ and using the proportionality $D_{\mathrm{g}} \propto T^{\frac{1}{2}}$ in Eq. (24), we find

$$
\alpha^{\frac{1}{2}}(1+A) \simeq \exp (Q / 2 R T) .
$$

In this case, a graph of $\ln \left[\alpha^{\frac{1}{2}}(1+A)\right]$ as a function of $1 / T$ should yield a straight line with slope $Q / 2 R$.

Figure 13 shows the experimental results for $\mathrm{CO}_{2}$ plotted in the form of $\ln \left[\alpha^{\frac{1}{2}}(1+A)\right]$ as a function of $1 / T$. A straight line with a slope of $1450^{\circ} \mathrm{K}$ may be drawn through the points for $T>300^{\circ} \mathrm{K}$. Hence Eq. (25) implies that

$$
Q \simeq 5800 \mathrm{cal} / \mathrm{mole} \text { for } D_{\mathrm{g}} \gg A D_{\mathrm{a}},
$$

and, because $E$ is necessarily smaller than $Q$, Eq. (23) implies that

$$
Q \geq 5800 \mathrm{cal} / \mathrm{mole} \text { for } D_{\mathrm{g}} \ll A D_{\mathrm{a}} .
$$

The temperature dependence of the heat of adsorption of $\mathrm{CO}_{2}$ on silica gel has been investigated by Kälberer and Schuster. ${ }^{9}$ For pressures much smaller than one atmosphere, they obtained 7200 $\mathrm{cal} / \mathrm{mole}$ at $0^{\circ} \mathrm{C}$ and $5370 \mathrm{cal} / \mathrm{mole}$ at $75^{\circ} \mathrm{C}-\mathrm{a}$ decrease of $1830 \mathrm{cal} / \mathrm{mole}$ for a temperature increase of $75^{\circ} \mathrm{C}$. For pressures near $\frac{1}{2}$ atmosphere, they obtained about $6300 \mathrm{cal} / \mathrm{mole}$ at $0^{\circ} \mathrm{C}$ and about $5600 \mathrm{cal} / \mathrm{mole}$ at $75^{\circ} \mathrm{C}-\mathrm{a}$ decrease of 700 $\mathrm{cal} / \mathrm{mole}$ for a temperature increase of $75^{\circ} \mathrm{C}$. In our experiments, the pressure varied from about $740 \mathrm{~mm} \mathrm{Hg}$ to $100 \mathrm{~mm} \mathrm{Hg}$; hence, estimates for the heat of desorption based on literature data are about $6600 \mathrm{cal} / \mathrm{mole}$ for $T \simeq-30^{\circ} \mathrm{C}$ and about $5100 \mathrm{cal} / \mathrm{mole}$ for $T \simeq 120^{\circ} \mathrm{C}$ and are, therefore, in fair agreement with our experimentally determined results. 


\section{ACKNOWLEDGMENTS}

These studies were supported by the U. S. Army Research Office (Durham) under Grant No. DAARO(D)-31-124-G289.

\section{APPENDIX A: APPROXIMATE JUSTIFICATION OF THE ASSUMPTION THAT THE SILICA GEL SYSTEM REMAINS EFFECTIVELY ISOTHERMAL}

Furnas $^{12}$ has studied experimentally the heat transfer rates from a stream of heated gases to a bed of particles in a cylindrical pipe and has used theoretical results of Schumann ${ }^{13}$ to correlate the data. Using the Furnas-Schumann equation and the assumption that the gas velocity in our experiments varies linearly with the distance from the bottom of the chamber, we may estimate representative heat transfer rates as a function of the temperature drop $\Delta T$. It then follows from Eq. (17) that the rate of heat addition necessary to maintain the system isothermal is

$$
\dot{Q}=\left(p_{0} V / t^{*}\right)(1-b) \exp \left(-t / t^{*}\right)
$$

for typical experiments at $T_{0}=300^{\circ} \mathrm{K}$ and $p_{0}=1$ atm, where $V=555 \mathrm{~cm}^{3}, t^{*}=0.19$ and $b=0.19$ for $\mathrm{Ar}, t^{*}=0.06$ and $b=0.1$ for $\mathrm{He}$, and $t^{*}=0.22$ and $b=0.6$ for $\mathrm{CO}_{2}$. Since the rate of heat addition necessary to maintain the system isothermal is the maximum rate of heat transfer, we may obtain upper limits for $\Delta T$ by equating $\mathrm{Eq}$. (A1) to the heat transfer rate expression of Furnas. Taking averages over the period of time $t_{\mathrm{f}}$ for typical experiments, and denoting the time average of $\Delta T$ by $\overline{\Delta T}$, we find that

$\overline{\Delta T}< \begin{cases}2^{\circ} \mathrm{C} & \text { for } \mathrm{Ar} \text { with } t_{\mathrm{f}}=0.60 \mathrm{sec}, \\ 4^{\circ} \mathrm{C} & \text { for } \mathrm{He} \text { with } t_{\mathrm{f}}=0.15 \mathrm{sec}, \\ 1^{\circ} \mathrm{C} & \text { for } \mathrm{CO}_{2} \text { with } t_{\mathrm{f}}=0.60 \mathrm{sec} ;\end{cases}$

the test durations $t_{\mathrm{f}}$ correspond, approximately, to the duration of sonic conditions in the nozzle throat. The values obtained in Eq. (A2) are constant, to within about one degree, for initial chamber temperatures in the range $230^{\circ} \mathrm{K}$ to $390^{\circ} \mathrm{K}$.

Equation (A2) is an expression for the required time average of the temperature difference between the bead surface and the nearly isothermal gas. But we are actually interested in the temperature drop of the gas during the course of a run. The bead surface temperature drop is determined by the sum of (a) the temperature drop $\Delta T_{\mathrm{h}}$ corresponding to energy loss by convection to the gas and (b) by the temperature drop $\Delta T_{\mathrm{d}}$ associated with endothermic

${ }^{12}$ C. C. Furnas, Ind. Eng. Chem. 22, 721 (1930).

${ }^{13}$ T. E. W. Schumann, J. Franklin Inst. 208, 305 (1929). desorption of gas from the bead. An upper limit to $\Delta T_{\mathrm{h}}$ may be obtained by solving the thermal diffusion equation ${ }^{14}$ in a spherical bead using as boundary condition the appropriate constant rate of energy loss from each bead. In this manner we find the following temperature changes:

$$
\Delta T_{\mathrm{h}} \simeq\left\{\begin{aligned}
0.1^{\circ} \mathrm{C} & \text { for } \mathrm{Ar}, \\
0.2^{\circ} \mathrm{C} & \text { for } \mathrm{He}, \\
0.05^{\circ} \mathrm{C} & \text { for } \mathrm{CO}_{2},
\end{aligned}\right.
$$

where appropriate thermal and transport properties ${ }^{15}$ have been employed. The drop in surface temperature of the bead $\Delta T_{\mathrm{d}}$ associated with the heat of desorption depends on the rates and heats of the desorption processes. If very little gas is adsorbed and desorbed from the solid, as in the experiments with $\mathrm{He}$, then $\Delta T_{\mathrm{d}}$ will be approximately zero. If significant adsorption occurs, we must investigate the relative magnitude of gaseous diffusion compared to surface diffusion (see Appendix B) before an estimate of $\Delta T_{\mathrm{d}}$ can be made. It is clear that any estimate of $\Delta T_{\mathrm{d}}$ will be very crude. In view of the known heats of adsorption, ${ }^{16,17}$ we would expect $\Delta T_{\mathrm{d}}$ to be larger for $\mathrm{CO}_{2}$ than for $\mathrm{Ar}$ and to be negligibly small for He. Measurements of the temperature decrease of the gas-silica gel system after the completion of each run, using a number of thermocouples at various locations in the chamber, indicated that the temperature drop for $\mathrm{CO}_{2}$ was about $3^{\circ} \mathrm{C}$ at an initial temperature of $115^{\circ} \mathrm{C}$ and about $10^{\circ} \mathrm{C}$ at an initial temperature of $25^{\circ} \mathrm{C}$. For $\mathrm{Ar}$ and $\mathrm{He}$, on the other hand, the temperature decrease was found to be about $1^{\circ} \mathrm{C}$ at all initial temperatures. These measurements suggest that the effects of the heats of desorption are not large.

The experimental measurements of chamber pressure as a function of time for the $\mathrm{CO}_{2-}^{-}, \mathrm{Ar}-$, and $\mathrm{He}-$ quartz sand systems agree well with the theoretical curve for an isothermal system without mass addition (see Fig. 3). Thus the analysis and experimental data indicate (a) that the temperature of the beads is approximately constant and equal to $T_{0}$ during a run and (b) that heat transfer rates are sufficiently high to maintain the gas system effectively isothermal. [A more detailed justification for the assumption that the system is effectively isothermal is given in reference 6.]

${ }^{14}$ H. S. Carslaw and J. C. Jaeger, Conduction of Heat in Solids (Oxford University Press, Oxford, England, 1959),
2nd ed., p. 242.

${ }_{15}$ C. L. Mantell, Adsorption (MrGraw-Hill Book Company, Inc., New York, 1951), p. 176.

${ }_{16}$ Reference 2, pp. 234, 240, 263.

17 Reference 9. 


\section{APPENDIX B: DETERMINATION OF THE OVERALL RATE OF DESORPTION OF GAS FROM HIGHLY POROUS SPHERES}

It is assumed that the desorption of gas from a highly porous sphere obeys the spherically symmetric diffusion equation. In particular, we assume that the radius of the average pore in the solid is small compared to the mean free path in the gas but large compared to the dimensions of a molecule so that Knudsen or free molecule flow occurs in the gas. [Assuming that the pores are cylindrical and have a small radius compared to the mean free path of the gas molecules, the Knudsen diffusion coefficient may be approximated, according to the kinetic theory of gases, ${ }^{18}$ by the relation

$$
D_{\mathrm{g}}=\frac{2}{3} a_{\mathrm{p}} \bar{v}
$$

where $a_{\mathfrak{p}}$ is a radius of the cylindrical pores, $\bar{v}=$ $\left(8 R_{\mathrm{g}} T / \pi\right)^{\frac{1}{2}}$ is the average molecular velocity of a perfect gas according to kinetic theory, and $T$ represents the absolute temperature of the gas. The ratio $a_{\mathfrak{p}} / \lambda$ (where $\lambda$ is the mean free path at STP) for silica gel with pore radius ${ }^{15} a_{\mathrm{p}} \simeq 2 \times 10^{-7} \mathrm{~cm}$ is estimated to be about $4 \times 10^{-2}$. It can be seen that $D_{\mathrm{g}}$ depends on molecular weight but not on molecular size. If the pore radius is not large compared to the dimensions of a molecule, the flow must depend on molecular size and Knudsen diffusion no longer applies.]

Since the surface concentration of adsorbed molecules depends on the pressure, a pressure gradient in the gas phase will, in general, give rise to a concentration gradient in the adsorbed phase. We assume that flow of gas in a porous solid occurs by diffusion in the gas phase (Knudsen diffusion) and by surface diffusion in the adsorbed phase. ${ }^{3,19}$ The assumption that the pore radius is large compared to the dimensions of a molecule implies that the thickness of the adsorbed layer remains negligibly small compared to the pore diameter. A schematic diagram of a typical pore in a highly porous spherical particle is shown in Fig. 14.

The diffusion equations may be written as

$$
\frac{\partial \rho_{\mathrm{g}}}{\partial t}=\frac{D_{\mathrm{g}}}{r^{2}} \frac{\partial}{\partial r}\left(r^{2} \frac{\partial \rho_{\mathrm{g}}}{\partial r}\right)+\dot{G},
$$

and

$$
\frac{\partial \rho_{\mathrm{a}}}{\partial t}=\frac{D_{\mathrm{a}}}{r^{2}} \frac{\partial}{\partial r}\left(r^{2} \frac{\partial \rho_{\mathrm{a}}}{\partial r}\right)-\dot{G},
$$

where $\rho_{\mathrm{a}}$ is the mass of adsorbed gas per unit volume

\footnotetext{
${ }^{18}$ R. D. Present, Kinetic Theory of Gases (McGraw-Hill Book Company, Inc.. New York, 1958), pp. 55-61.

${ }^{19}$ R. M. Barrer and J. A. Barrie, Proc. Roy Soc. (London) A213, 250 (1952).
}

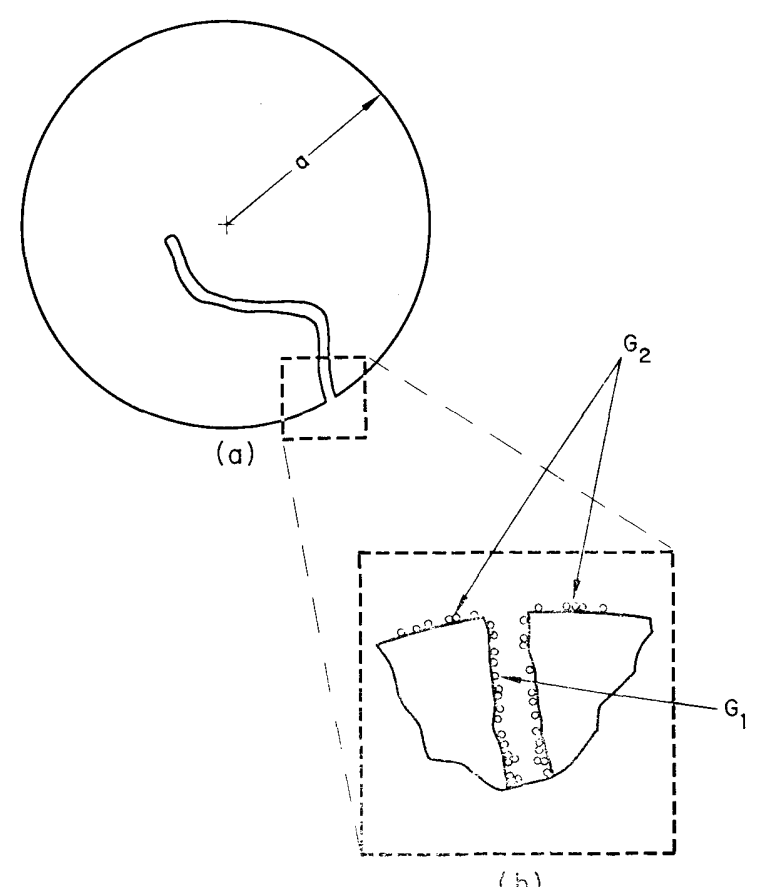

(b)

FIg. 14. Schematic diagram of a typical pore in a highly porous spherical particle. (a) A spherical particle showing a typical pore with average radius $a_{\mathrm{p}}$. (b) Enlarged section of pore opening at the external surface of the particle.

$\mathrm{G}_{1}$ : gas molecules adsorbed on the external surface are negligibly small in number compared to the number of molecules adsorbed on the pore walls within the solid. $\mathrm{G}_{2}$ : gas molecules adsorbed on the pore walls; $\rho_{2}(r, t)$ is the average concentration of the adsorbed molecules in $\mathrm{g} / \mathrm{cm}^{3}$ of adsorbent, where $r=$ radius from the center of the particle. The corresponding density of molecules in the gas phase (not shown in the figure) within the pores is $\rho_{g}(r, t)$.

of adsorbent, $\rho_{\mathrm{g}}$ is the mass of the gaseous phase per unit volume of adsorbent, $D_{\mathrm{g}}$ and $D_{\mathrm{a}}$ are, respectively, the Knudsen diffusion coefficient and the apparent surface diffusion coefficient, and $\dot{G}$ represents the rate of mass transfer per unit volume from the adsorbed phase to the gas phase within the porous solid (thus $\dot{G}$ is positive for desorption and negative for adsorption). In Eqs. (B1a) and (B1b) it has been assumed (a) that $D_{\mathrm{g}}$ and $D_{\mathrm{a}}$ are independent of concentration, (b) that the porosity $\epsilon$, defined as the pore volume divided by the total volume of the sphere, is independent of $r$, (c) that the pore radius $a_{\mathrm{p}}$ is uniform throughout the sphere, and (d) that the adsorbed molecules on the pore walls are limited to a monolayer. Adding Eqs. (B1a) and (B1b), we obtain

$$
\begin{aligned}
\frac{\partial}{\partial t}\left(\rho_{\mathrm{a}}+\rho_{\mathrm{g}}\right)=\frac{D_{\mathrm{g}}}{r^{2}} \frac{\partial}{\partial r}\left(r^{2}\right. & \left.\frac{\partial \rho_{\mathrm{g}}}{\partial r}\right) \\
& +\frac{D_{\mathrm{a}}}{r^{2}} \frac{\partial}{\partial r}\left(r^{2} \frac{\partial \rho_{\mathrm{a}}}{\partial r}\right),
\end{aligned}
$$

thus eliminating $\dot{G}$ from the equations. 
In the following analysis, we assume [for justification, see the remarks following Eq. (B13)] that, at the surfaces of the porous solid, the adsorbed phase and the gas are in equilibrium at all times and that the relation

$$
\rho_{\mathrm{a}}(r, t)=A \rho_{\mathrm{g}}(r, t)+B
$$

applies. Here $A=$ (constant) [exp $(Q / R T)]$ is a function of the temperature with $Q$ representing the molar heat of adsorption; $B$ is also a function of the temperature.

Combining Eqs. (B2) and (B3), under isothermal conditions, yields the result

$$
\frac{\partial \rho_{\mathrm{g}}}{\partial t}=\frac{D}{r^{2}} \frac{\partial}{\partial r}\left(r^{2} \frac{\partial \rho_{\mathrm{g}}}{\partial r}\right)
$$

where

$$
D \equiv\left(D_{\mathrm{g}}+A D_{\mathrm{a}}\right) /(1+A) .
$$

The applicable boundary conditions are

$$
\rho_{\mathrm{g}}(r, 0)=\epsilon \rho_{0}, \quad \text { and } \rho_{\mathrm{g}}(a, t)=\epsilon \rho(t)
$$

where $a$ is the radius of the sphere, $\rho_{0}$ is the initial density of gas external to the sphere, and $\rho(t)$ is the variable external density of the gas. Equation (B4) may now be solved with the result ${ }^{20}$

$$
\begin{aligned}
& {\left[\rho_{\mathrm{g}}(r, t)-\epsilon \rho_{0}\right]=-\frac{2 \epsilon D}{r a} \sum_{n=1}^{\infty}\left\{(-1)^{n} n \pi\left(\sin \frac{n \pi r}{a}\right)\right.} \\
& \left.\cdot \exp \left(-n^{2} \pi^{2} t / t_{\mathrm{d}}\right) \int_{0}^{t}\left[\rho(x)-\rho_{0}\right] \exp \left(n^{2} \pi^{2} x / t_{\mathrm{d}}\right) d x\right\},
\end{aligned}
$$

where $t_{\mathrm{d}}=a^{2} / D$. When the external concentration varies according to Eq. (8), viz.,

$$
\rho(t)-\rho_{0}=-\left(1-b_{0}\right)\left[1-\exp \left(-t / t^{*}\right)\right] \rho_{0},
$$

then Eq. (B6) leads to the result

$$
\begin{aligned}
& {\left[\rho_{\mathrm{g}}(r, t)-\epsilon \rho_{0}\right]} \\
& =\epsilon \rho_{0}\left(1-b_{0}\right)\left\{-1+\frac{a}{r} \frac{\sin \left[\left(t_{\mathrm{d}} / t^{*}\right) r / a\right]}{\sin \left(t_{\mathrm{d}} / t^{*}\right)^{\frac{1}{2}}}\left[\exp \left(-\frac{t}{t^{*}}\right)\right]\right. \\
& \left.+\frac{2 a}{\pi r} \sum_{n=1}^{\infty}(-1)^{n} \frac{(\sin n \pi r / a) \exp \left(-n^{2} \pi^{2} t / t_{\mathrm{d}}\right)}{n\left[\left(n^{2} \pi^{2} t^{*} / i_{\mathrm{d}}\right)-1\right]}\right\} \cdot(\mathrm{B} 7)
\end{aligned}
$$

The rate of mass diffusion across the surface of a single sphere is

$$
\dot{m}=-\left[4 \pi r^{2}\left(D_{\mathrm{a}} \frac{\partial \rho_{\mathrm{a}}}{\partial r}+D_{\mathrm{g}} \frac{\partial \rho_{\mathrm{g}}}{\partial r}\right)\right]_{r=a},
$$

or, using Eq. (B3),

$$
\dot{m}=-\left[4 \pi r^{2}\left(D_{\mathrm{g}}+A D_{\mathrm{a}}\right) \partial \rho_{\mathrm{g}} / \partial r\right]_{r=a},
$$

${ }^{20}$ Reference 14, p. 233. which becomes, in view of Eq. (B7),

$$
\begin{aligned}
& \dot{m}=4 \pi a\left(1-b_{0}\right) \epsilon \rho_{0}\left(D_{\mathrm{g}}+A D_{\mathrm{a}}\right) \\
& \cdot\left\{\left[1-\left(\frac{t_{\mathrm{d}}}{t^{*}}\right)^{\frac{1}{2}} \cot \left(\frac{t_{\mathrm{d}}}{t^{*}}\right)^{\frac{1}{2}} \exp \left(-\frac{t}{t^{*}}\right)\right.\right. \\
&\left.-2 \sum_{n=1}^{\infty} \frac{\exp \left(-n^{2} \pi^{2} t / t_{\mathrm{d}}\right)}{\left[\left(n^{2} \pi^{2} t^{*} / t_{\mathrm{d}}\right)-1\right]}\right\} .
\end{aligned}
$$

By writing a Fourier series for cot $\left[\left(t_{\mathrm{d}} / t^{*}\right)^{\frac{1}{2}}\right] x$ and setting $x=1$, we obtain

$$
1-\left(\frac{t_{\mathrm{d}}}{t^{*}}\right)^{\frac{1}{2}} \cot \left(\frac{t_{\mathrm{d}}}{t^{*}}\right)^{\frac{1}{2}}=2 \sum_{n=1}^{\infty} \frac{1}{\left[\left(n^{2} \pi^{2} t^{*} / t_{\mathrm{d}}\right)-1\right]} .
$$

Hence Eq. (B8) may be rewritten as

$$
\begin{aligned}
\dot{m}= & 8 \pi a\left(1-b_{0}\right) \epsilon \rho_{0}\left(D_{\mathrm{g}}+A D_{\mathrm{a}}\right) \\
\cdot & \sum_{n=1}^{\infty}\left\{\frac{\exp \left(-t / t^{*}\right)-\exp \left(-n^{2} \pi^{2} t / t_{\mathrm{d}}\right)}{\left[\left(n^{2} \pi^{2} t^{*} / t_{\mathrm{d}}\right)-1\right]}\right\} .
\end{aligned}
$$

The total rate of mass addition from $N$ spheres is

$$
\dot{m}_{\mathrm{d}}=N \dot{m}=\left(m_{\mathrm{b}} / \frac{4}{3} \pi a^{3} \rho_{\mathrm{b}}\right) \dot{m},
$$

where $m_{\mathrm{b}}$ and $\rho_{\mathrm{b}}$ are, respectively, the total mass and the apparent density of the spheres. Substituting Eq. (B10) into Eq. (B11) we obtain the desired result, viz.,

$$
\begin{gathered}
\dot{m}_{\mathrm{d}}=6\left(1-b_{0}\right) \frac{\epsilon \rho_{0}}{\rho_{\mathrm{b}}} \frac{m_{\mathrm{b}}}{a^{2}}\left(D_{\mathrm{g}}+A D_{\mathrm{a}}\right) \\
\cdot \sum_{n=1}^{\infty}\left\{\frac{\exp \left(-t / t^{*}\right)-\exp \left(-n^{2} \pi^{2} t / t_{\mathrm{d}}\right)}{\left[\left(n^{2} \pi^{2} t^{*} / t_{\mathrm{d}}\right)-1\right]}\right\},
\end{gathered}
$$

or

$$
\begin{gathered}
b=\left(\frac{\dot{m}_{\mathrm{d}} t^{*}}{m_{0}}\right)=6 \epsilon\left(1-b_{0}\right)\left(\frac{1-f}{f}\right)(1+A)\left(\frac{t^{*}}{t_{\mathrm{d}}}\right) \\
\cdot \sum_{n=1}^{\infty}\left\{\frac{\exp \left(-t / t^{*}\right)-\exp \left(-n^{2} \pi^{2} t / t_{\mathrm{d}}\right)}{\left[\left(n^{2} \pi^{2} t^{*} / t_{\mathrm{d}}\right)-1\right]}\right\},
\end{gathered}
$$

where $(1-f) / f$ is equal to $\rho_{0} m_{\mathrm{b}} / \rho_{\mathrm{b}} m_{0}$ if $f$ is the fractional void in the bed.

For the case where very little gas is adsorbed, we set $A=0$ in Eq. (B13) and $t_{\mathrm{d}} \simeq a^{2} / D_{\mathrm{g}}$. For significant adsorption, but $A D_{\mathrm{a}} \ll D_{\mathrm{g}}, t_{\mathrm{d}} \simeq a^{2}(1+A) / D_{\mathrm{g}}$; finally, for $D_{\mathrm{g}} \ll A D_{\mathrm{a}}, t_{\mathrm{d}} \simeq a^{2}(1+A) / A D_{\mathrm{a}}$.

In conclusion, it is appropriate to justify the use of Eq. (B3). It has been found experimentally that the adsorption isotherms of $\mathrm{Ar}$ and $\mathrm{CO}_{2}$ on silica gel are approximately linear over a wide range of pressures. ${ }^{21,22}$ The multimolecular adsorption theory of Brunauer, Emmett, and Teller ${ }^{23}$ provides a general

${ }^{21}$ W. A. Patrick, W. C. Preston, and A. E. Owens, J. Phys. Chem. 29, 421 (1925).

${ }_{22}$ Reference 2 , pp. $16,68-70$.

${ }^{23} \mathrm{~S}$. Brunauer, P. H. Emmett, and E. Teller, J. Am. Chem. Soc. 60, 309 (1938). 
equation which, under certain conditions, also yields a linear isotherm over a wide range of pressures (see, for example, reference 24, p. 479, Fig. XI-8). In particular, a linear isotherm is observed when the heat of adsorption in the second and succeeding layers is approximately equal to the heat of adsorption in the first layer, i.e., multilayer adsorption occurs to some extent before the bare surface is covered with a monolayer. In other words, the use of Eq. (B3) does not necessarily imply monomolecular adsorption. Direct experimental justification is provided, for example, by the fact that Eq. (B3) holds for adsorption of $\mathrm{CO}_{2}$ on silica gel after the monolayer has been filled..$^{22,25}$ It should be noted, however, that the theory which has been developed from Eqs. (B1a) and (B1b) is valid only for monomolecular adsorption.

The following limiting cases of Eq. (B13) are of some interest. For the case where $t^{*} / t_{\mathrm{d}} \ll 1$, the discharge time is much shorter than the diffusion time. Since $t^{*}$ is small, the external density drops rapidly to the value $\rho / \rho_{0}=b_{0}$ [see Eq. (8)].

Equation (B13) may be rewritten in the form

$b=6 \epsilon\left(1-b_{0}\right)\left(\frac{1-f}{f}\right)(1+A)[\exp (-\tau)] S(\tau ; \alpha)$,

where $\alpha=t^{*} / t_{\mathrm{d}}, \tau=t / t^{*}$, and

$S(\tau ; \alpha) \equiv \alpha \sum_{n=1}^{\infty}\left\{\frac{1-\exp \left[-\left(\alpha n^{2} \pi^{2}-1\right) \tau\right]}{\left(\alpha n^{2} \pi^{2}-1\right)}\right\}$.

Differentiating $S(\tau ; \alpha)$ with respect to $\tau$ yields

$$
\frac{d S}{d \tau}=\alpha \exp (\tau) \sum_{n=1}^{\infty} \exp \left(-\alpha n^{2} \pi^{2} \tau\right)
$$

or,

$\frac{d S}{d \tau}=\alpha \exp (\tau)\left\{\sum_{n=0}^{\infty}\left[\exp \left(-\alpha n^{2} \pi^{2} \tau\right)\right]-1\right\}$.

For very small $\alpha$, we may evaluate the sum by using the Euler-Maclaurin sum formula with the result

$$
\begin{gathered}
\sum_{n=0}^{\infty} \exp \left(-\alpha n^{2} \pi^{2} \tau\right)=\int_{0}^{\infty} \exp \left(-\alpha n^{2} \pi^{2} \tau\right) d n+\frac{1}{2} \\
=\frac{1}{\pi \alpha^{\frac{1}{2}}} \int_{0}^{\infty} \exp \left(-\tau y^{2}\right) d y+\frac{1}{2},
\end{gathered}
$$

whence it follows that

$$
\sum_{n=0}^{\infty} \exp \left(-\alpha n^{2} \pi^{2} \tau\right)=\frac{1}{2(\pi \alpha \tau)^{\frac{T}{2}}}+\frac{1}{2} .
$$

${ }^{24}$ A. W. Adamson, Physical Chemistry of Surfaces (Interscience Publishers, Inc., New York, 1960), p. 479.

${ }^{25}$ Reference 2, pp. 286-291.
Substituting Eq. (B18) into Eq. (B16) we find, for sufficiently small values of $\alpha \tau$,

$$
\frac{d S}{d \tau} \simeq \frac{1}{2}\left(\frac{\alpha}{\pi}\right)^{\frac{1}{2}} \frac{\exp (\tau)}{\tau^{\frac{1}{2}}}
$$

From Eq. (B15), it can be seen that the value of $S(\tau ; \alpha)$ at $\tau=0$ is equal to zero; hence, we may integrate Eq. (B19) to obtain $S(\tau ; \alpha)$, viz.,

$$
\begin{aligned}
S(\tau ; \alpha) \simeq \frac{1}{2}\left(\frac{\alpha}{\pi}\right)^{\frac{1}{2}} \int_{0}^{\tau} \frac{\exp \left(t^{\prime}\right)}{\left(t^{\prime}\right)^{\frac{1}{2}}} d t^{\prime} & \\
& =\left(\frac{\alpha}{\pi}\right)^{\frac{1}{2}} \int_{0}^{\tau^{3}} \exp \left(t^{2}\right) d t
\end{aligned}
$$

for small $\alpha$. The integral in Eq. (B20) is tabulated in reference 26. Substituting Eq. (B20) into Eq. (B14) yields the desired result for small $\alpha$, viz.,

$$
\begin{aligned}
b \simeq 6 \epsilon\left(\frac{1-f}{f}\right)(1 & \left.-b_{0}\right)(1+A)\left(\frac{\alpha}{\pi}\right)^{\frac{1}{2}} \\
& \cdot \exp (-\tau) \int_{0}^{\tau^{3}} \exp \left(t^{2}\right) d t
\end{aligned}
$$

for small $\alpha$.

For the case where $t^{*} / t_{\mathrm{d}} \gg 1$, the process of mass addition by diffusion occurs very rapidly compared with the discharge rate, and the density within the pores decreases nearly as rapidly as the external density, i.e., the rate of desorption is determined by the external density. For $t>0$, Eq. (B13) then becomes, approximately,

$$
b \simeq \epsilon\left(1-b_{0}\right)\left(\frac{1-f}{f}\right)(1+A) \exp \left(-\frac{t}{t^{*}}\right) .
$$

\section{APPENDIX C: DERIVATION OF THE ENERGY EQUATION}

Consider a vessel containing gas and beads from which gases are desorbed while gas flow occurs through a de Laval nozzle. We construct a surface $S(t)$ bounding the volume $V(t)$ in which the gasbead system is contained. In this manner, we construct a thermodynamic system containing uniformly distributed sources. Applying the first law of thermodynamics, we may write the expression

$$
\begin{array}{r}
\frac{d}{d t} \int_{V(t)} \rho\left(e+\frac{1}{2} v^{2}\right) d V=\dot{m}_{\mathrm{d}}\left[c_{v} T_{\mathrm{d}}+\left(\frac{p}{\rho}\right)_{\mathrm{d}}\right] \\
+\int_{V(t)} \dot{q} d V+\int_{S(t)} \mathbf{v} \cdot(\sigma \mathbf{n}) d S
\end{array}
$$

${ }^{26}$ E. Jahnke and F. Emde, Tables of Functions (Dover Publications, New York, 1945), 4th ed., p. 32. 
corresponding to the statement

increase in energy of the system = energy supplied to the system through the boundaries or from imbedded sources + work done on the system.

Here the time derivative is the Euler time derivative following the fluid, $e$ is the internal energy per unit mass, $\frac{1}{2} v^{2}$ the kinetic energy per unit mass, $\dot{m}_{\mathrm{d}} c_{p} T_{\mathrm{d}}$ represents the rate of energy addition from the uniformly distributed sources at the temperature $T_{\mathrm{d}}$ associated with desorption of gas at the temperature $T_{\mathrm{d}}, \mathrm{v}$ is the velocity of the gas, $\dot{q}$ the rate of heat addition per unit volume of gas, $\sigma$ the stress tensor (with components $\sigma_{i j}=-p \delta_{i j}+\tau_{i j}$, where $\tau_{i j}$ is the $i j$ th component of the viscous stress tensor, $-p \delta_{i j}$ is the $i j$ th component of the pressure tensor), and $\mathrm{n}$ is the outward directed normal to $S(t)$. Using the general relation ${ }^{27}$

$$
\frac{d}{d t} \int_{V(t)} \rho f(\mathbf{x}, t) d V=\int_{V(t)} \rho \frac{d f(\mathbf{x}, t)}{d t} d V,
$$

we obtain the identity

$$
\frac{d}{d t} \int_{V(t)} \rho\left(e+\frac{1}{2} v^{2}\right) d V=\int_{V(t)} \rho \frac{d}{d t}\left(e+\frac{1}{2} v^{2}\right) d V .
$$

Furthermore, using the continuity equation $\partial \rho / \partial t+$ $\nabla \cdot(\rho \mathbf{v})=0$, and noting that $d / d t=\partial / \partial t+\mathbf{v} \cdot \nabla$, we find that

$$
\begin{aligned}
& \int_{V(t)} \rho \frac{d}{d t}\left(e+\frac{1}{2} v^{2}\right) d V \\
& =\int_{V(t)}\left\{\frac{\partial}{\partial t}\left[\rho\left(e+\frac{1}{2} v^{2}\right)\right]+\nabla \cdot\left[\rho \mathbf{v}\left(e+\frac{1}{2} v^{2}\right)\right]\right\} d V \\
& =\int_{V(t)} \frac{\partial}{\partial t}\left[\rho\left(e+\frac{1}{2} v^{2}\right)\right] d V+\int_{S(t)} \rho\left(e+\frac{1}{2} v^{2}\right) \mathbf{v} \cdot \mathbf{n} d S
\end{aligned}
$$

where Gauss' theorem has been applied. Neglecting

${ }^{27}$ See, for example, W. Nachbar, F. Williams, and S. S. Penner, Quart. Appl. Math. 17, 43 (1959). shearing stresses, Eq. (C1) becomes, therefore,

$$
\begin{aligned}
& \int_{V(t)}\left\{\frac{\partial}{\partial t}\left[\rho\left(e+\frac{1}{2} v^{2}\right)\right]-\dot{q}\right\} d V=\dot{m}_{\mathrm{d}} c_{p} T_{\mathrm{d}} \\
& -\int_{S(t)} p \mathbf{v} \cdot \mathbf{n} d S-\int_{S(t)} \rho\left(e+\frac{\mathbf{1}}{2} v^{2}\right) \mathbf{v} \cdot \mathbf{n} d S .
\end{aligned}
$$

It is now convenient to choose $S(t)$ as the surface bounding the chamber volume $V$. We may then integrate the term appearing on the left hand side of Eq. (C2) over the uniform container. Thus, we find for the integral the result

$$
(\partial / \partial t)\left(m c_{v} T\right)-\dot{Q}
$$

if $m$ denotes the total mass of free gas in the container at any time and $\dot{Q}$ represents the total rate of heat addition to the volume $V$. It is apparent that $\mathbf{v}=0$ everywhere on $S(t)$ except where mass is leaving from the chamber. Hence

$$
\begin{aligned}
& \int_{S(t)} p \mathbf{v} \cdot \mathbf{n} d S=\int_{S(t)} \frac{p}{\rho}(\rho \mathrm{v}) \cdot \mathbf{n} d S \\
&=\dot{m}_{\mathrm{e}}\left(\frac{p}{\rho}\right)_{\mathrm{e}}=\dot{m}_{\mathrm{e}} R_{\mathrm{g}} T_{\mathrm{e}}
\end{aligned}
$$

for ideal gases, where the subscript e identifies the uniform conditions at the exit plane and $\dot{m}_{\mathrm{e}}$ represents the mass flow rate out of the control volume $V$ (which equals the mass discharge rate through the de Laval nozzle). Similarly,

$$
\begin{aligned}
\int_{S(t)} \rho\left(e+\frac{1}{2} v^{2}\right) \mathbf{v} \cdot \mathbf{n} d S= & \left(e+\frac{1}{2} v^{2}\right)_{\mathrm{e}} \dot{m}_{\mathrm{e}} \\
& =\left(c_{v} T+\frac{1}{2} v^{2}\right)_{\mathrm{e}} \dot{m}_{\mathrm{e}} \simeq c_{v} T \dot{m}_{\mathrm{e}}
\end{aligned}
$$

since the translational energy per unit mass at the exit plane of the volume $V$ is negligibly small compared with the internal energy per unit mass at this same location.

Introducing the preceding relations into Eq. (C2), we obtain the desired result, viz.,

$$
(\partial / \partial t)\left(m c_{v} T\right)=\dot{Q}+\dot{m}_{\mathrm{d}} c_{p} T_{\mathrm{d}}-\dot{m}_{\mathrm{e}} c_{p} T .
$$

